\title{
Derechos Humanos: desarrollo y circunstancia ${ }^{1}$
}

Sergio García Ramírez

\section{Un asunto «explosivo y expansivo»}

Los derechos humanos son un signo de nuestro tiempo, ha escrito un tratadista ilustre. Concurren, sobre todo, al diseño del porvenir. Significaron una "revolución copernicana" en la forma de entender la relación política. Su historia es la del largo plazo, mejor que la del tiempo inmediato $^{2}$. Surgen y prosperan -o declinan- ahí donde se anima el antiguo encuentro inexorable entre el hombre y el poder. Este puede ser amo y servidor de aquél: que sea lo uno o lo otro ha sido el tema fundamental de la teoría política ${ }^{3}$, pero sobre todo de la práctica del poder: una práctica que ha acompañado al ser humano en el curso de su infinita travesía. Esa compañía, por cierto, persistirá. De ahí que también perdure, inagotable, el desvelo por los derechos humanos: un desvelo que cuida el sueño de la humanidad.

1 Este trabajo forma parte de un estudio más amplio, actualmente en proceso, elaborado por el autor en el Instituto de Investigaciones Jurídicas de la Universidad Nacional Autónoma de México.

2 Cfr: Norberto Bobbio, Letà dei diritti, Einaudi Tascabili, Torino, 1997, pp. 251 252,256 y 264 .

3 "Alfa y omega de la teoría política es el problema del poder: cómo se adquiere, se conserva y se pierde, cómo se ejerce y como se defiende [...]". Ahora bien, este mismo problema "puede ser considerado desde dos puntos de vista diversos, e incluso contrapuestos: exparte principis o exparte populi (desde la perspectiva del gobernante o desde la perspectiva del pueblo). Maquiavelo o Rosseau, para hablar de dos símbolos. La teoría de la razón de Estado o la teoría de los derechos naturales y el constitucionalismo". Ibidem, p. 157. 
Los derechos humanos constituyen un asunto explosivo y expansivo si se me permite emplear esta expresión-, que demandan y establecen sus propias garantías, tema de este ensayo. La explosión ha sido producto del trauma que se produjo al cabo de la Segunda Guerra mundial, y del consecuente fervor tutelar que aquél trajo consigo ${ }^{4}$. Después de esta conflagración se presentó un cambio radical: el desarrollo del Derecho internacional de los derechos humanos hizo que éstos no fuesen vistos más como un asunto doméstico; los individuos pasaron a ser sujetos del Derecho de gentes, dotados con la posibilidad, potencial o actual, de acceder a la justicia internacional ${ }^{5}$. El Estado ya no puede disponer a su arbitrio de los individuos que se hallan bajo su jurisdicción y, lo que es más importante, bajo su imperio en más de un sentido: de jure y de facto.

Es verdad que el siglo XX ha presenciado hechos de violencia exacerbada, que cobraron infinidad de víctimas en Asia y en Europa, generaron un inmenso dolor y una poderosa indignación, y culminaron en la reacción bienhechora -una reacción constructiva del nuevo Derecho de los derechos humanos- de la comunidad internacional al cabo de la Segunda Guerra. Pero también es verdad que semejante violencia no es patrimonio de esa centuria ni de ciertos territorios. La hubo, desenfrenada, en siglos anteriores, cuando no se hablaba de derechos humanos, libertades civiles, derechos fundamentales, pero se hallaban puestas las bases morales para ellos.

Los pueblos americanos y africanos cuentan con una dura experiencia en este campo: a su manera, con sus propias versiones. En América se tiene la historia del etnocidio asociado a la conquista y a la colonización $^{6}$, y África fue el escenario de innumerables correrías consumadas

4 «Si es cierto que el siglo XX ha sido palco de crueldades perpetradas contra la persona humana en escala sin precedentes, también es cier to que esto ha generado una reacción -igualmente sin precedentes- en contra de tales atrocidades y abusos, como manifestación del despertar de la conciencia jurídica universal para las necesidades apremiantes de protección del ser humano". Antônio A. Cançado Trindade, "Prólogo" en AAVV.- El sistema interamericano de protección de los derechos humanos en el umbral del siglo XXI. Memoria del Seminario. Noviembre de 1999, San José, Costa Rica, Corte Interamericana de Derechos Humanos, 2001, t. I, p. XXIII.

5 En este sentido, $c f r$ Janusz Symonides, "Access of individuals to international tribunals and international human rights complaints procedures", en AAVV.- El sistema interamericano..., op. cit., t. I, p. 482.

6 «La fuerza militar, la mayor capacidad de matar, fue el pilar que sustentó el orden colonial: el argumento último y contundente de la dominación». Guillermo Bonfil 
por los cazadores de esclavos ${ }^{7}$. Se debe recordar el despoblamiento que hubo en Mesoamérica, ampliamente documentado ${ }^{8}$. La suerte de los indígenas no fue mejor que la de otros pueblos, victimados en el curso del siglo XX. Ahí están, para acreditarlo, los testimonios de Fray Bartolomé de Las Casas -a quien se ha querido imputar, sin embargo, el establecimiento de una "leyenda negra" ". El liberalismo del siglo XIX no rescató los derechos de los indígenas, sino pugnó contra éstos: la

Batalla, México profundo. Una civilización negada, México, Grijalbo, 2001, p. 126. Siempre es aleccionadora la lectura de la obra notable de Miguel León Portilla, y Ángel María Garibay, Visión de los vencidos. Relaciones indígenas de la conquista, $18^{\mathrm{a}} \mathrm{ed}$., México, UNAM, 2000. La toma del Templo Mayor propone el estilo de la conquista: «Luego se meten (los conquistadores) primeramente dentro de las casas (del templo) para matar a todos: a los que acarreaban el agua, a los que traían la pastura de los caballos, a los que molían, a los que barrían, a los que estaban de vigilancia». Ibidem, p. 138. Tiene algo más que significado físico la expresión del narrador indígena que refiere lo ocurrido tras la caída de la ciudad imperial: «Y ya no teníamos escudos, ya no teníamos macanas, y nada teníamos que comer [...]. Y toda la noche llovió sobre nosotros». Ibidem, p. 154.

7 No es fácil conocer el número de africanos transportados a través del Atlántico para servir como esclavos. Las estimaciones varían. Se habla de alrededor de diez millones de desembarcados, pero a esta cifra hay que añadir la de quienes murieron en la travesía y la de innumerables víctimas -inmediatamente o al cabo de cierto tiempocomo consecuencia del proceso de captura, que diezmaba poblaciones y causaba enormes daños actuales o futuros a sus habitantes. Cfr. Pierre Bertaux, Africa. Desde la prehistoria hasta los Estados actuales, trad. de Manuel Ramón Alarcón, 18ª . ed., México, Siglo Veintiuno Editores, 1998, p. 134.

8 Bonfil Batalla invoca las estimaciones de D. N. Cook y W. Borah, a propósito de la población indígena de México central en años de la conquista y la colonia: 1519, 15.3 millones; 1523, 16.8 millones; 1548, 2.6 millones; 1595, 1 millón 300 mil; y 1605, un millón. "Otras estimaciones -agrega- señalan que la población del valle de México descendió de aproximadamente 3 millones de habitantes en 1519 a sólo 70 mil indios a mediados del siglo XVII; los primeros años inmediatos a la caída de Tenochtitlan arrojan un saldo pavoroso, ya que para 1524 los habitantes del valle se han reducido a la tercera parte. La población india comienza a crecer lentamente a partir de la segunda mitad del siglo XVII, pero México alcanzará a tener una población semejante a la que habitaba su territorio en 1519, sólo bien entrado el presente siglo». Concluye, con énfasis: «Estos son los hechos». México profundo..., op. cit., pp. 127-128.

9 Las Casas, que menciona a los indígenas como "ovejas mansas", relata que en el curso de los cuarenta años posteriores a la conquista, los conquistadores "no han hecho [...] sino despedazarlas, matarlas, angustiarlas, afligirlas, atormentarlas y destruirlas, por las extrañas, y varias y nunca vistas, ni leídas, ni oídas maneras de crueldad". Doctrina, 5a. ed., México, UNAM, 1992, p. 5. 
respuesta gubernamental a las reclamaciones indígenas fue la represión militar ${ }^{10}$. Tampoco se podría olvidar, por supuesto, la histórica devastación que han traído consigo las numerosas dictaduras que sometieron a nuestros pueblos ${ }^{11}$, bajo un sistema de represión que tal vez comienza a disiparse $^{12}$.

Aquello -el drama europeo- auspició el fortalecimiento del constitucionalismo, por una parte -que implica una "técnica de la libertad" ${ }^{13}$-, y la

10 Cfr. Carlos Montemayor, Los pueblos indios de México hoy, México, Temas de hoy, 2000 , pp. 65 y 77.

11 Desde la dictadura de Porfirio Díaz, de la que John Kenneth Turner dejó constancias abrumadoras ( México es un país sin libertad política, sin libertad de palabra, sin prensa libre, sin elecciones libres, sin sistema judicial, sin partidos políticos, sin ninguna de nuestras queridas garantías individuales, sin libertad para conseguir la felicidad». México bárbaro, México, Ed. Época, 2001, p. 7), hasta la guerra sucia en el Cono Sur del Continente; por ejemplo, «esos largos años de violencia y extermino en la Argentina, donde seguramente murieron 10,000 personas y 15,000 más desaparecieron". Jacobo Timerman, Preso sin nombre, celda sin número, Nueva York, Random Editores, 1981, p. 15. Se ha dicho que en este pais la ofensiva contra el «enemigo interno" -en procuración de una nación "blanca, occidental y cristiana"-, "fue el pretexto para desencadenar una represión que se calcula ha costado más de treinta mil muertos". Luis Díaz Muller, América Latina. Relaciones internacionales y derechos humanos, México, Fondo de Cultura Económica, 1986, p. 207. En 1982, César Sepúlveda observaba: "estamos testificando un panorama desolador, preocupante, que no se había presentado antes, ni con tintes tan sombríos. Es impresionante la lista de países a los que se imputan ataques despiadados y arteros contra las libertades, la dignidad y la vida de las personas, generalmente opositores conscientes a un régimen gubernamental". Estudios sobre Derecho internacional y derechos humanos, México, Comisión Nacional de Derechos Humanos, 1991, p. 41.

12 «La militarización del poder se entrelaza con la universalización de la represión", expone Marcos Kaplan en un examen de lo ocurrido en países suramericanos; en este esquema de poder, se "convierte la violencia en la solución privilegiada para todo problema o conflicto. La represión se universaliza en sus objetivos, en sus destinatarios y formas, en sus niveles y aspectos. Sus medios aumentan en número, refinamiento, intensidad y eficacia. Se rompe más aún el equilibrio entre la represión estatal y paraestatal y la capacidad defensiva y ofensiva de grupos e instituciones de la sociedad civil. Se obstaculizan y se destruyen las organizaciones y movimientos, los procesos de concientización y movilización de los sectores medios y populares; se refuerza la despolitización, el conformismo y la apatía, la automarginación". El Estado latinoamericano, México, UNAM, Instituto de Investigaciones Jurídicas, 1996, p. 268.

13 La sugerente expresión es de Matteucci, op. cit. Pedro de Vega, "Mundialización y Derecho constitucional: la crisis del principio democrático en el constitucionalismo actual", en Miguel Carbonell y Rodolfo Vázquez (comps.), Estado constitucional y 
plena asunción del individuo como sujeto del Derecho internacional, por la otra ${ }^{14}$. Esto último se escrituró definitivamente en una serie de instrumentos sucesivos -con precedentes estimables y desarrollos numerosos-, tanto generales como regionales: las Cartas de la Organización de las Naciones Unidas ${ }^{15}$ y la Organización de los Estados America$\operatorname{nos}^{16}$, la Declaración Universal de los Derechos Humanos $(1948)^{17}$, la

globalización, México, UNAM, Instituto de Investigaciones Jurídicas/Ed. Porrúa, 2001, p. 177. De Vega explica la conformación ideológica de la ideología del constitucionalismo: «a los elementos liberales extraídos de la experiencia inglesa (principio liberal del constitucionalismo), pronto se sumarían los supuestos democráticos derivados de la doctrina contractualista (principio democrático del constitucionalismo), de clara raigambre continentaly. Ibidem, p.179. El proceso histórico del Estado constitucional moderno se halla "coronado en la actualidad, por un lado, por un abigarrado conjunto de técnicas jurídicas garantizadoras de la libertad, que culminaron con la creación de los tribunales constitucionales y, por otro, por un complejo sistema de mecanismos limitadores y controladores del poder que enriquecieron los viejos criterios del garantismo". Ibidem, p. 185.

14 Cfr. Sergio García Ramírez, Los derechos humanos y el Derecho penal, 2a. ed., México, Miguel Ángel Porrúa, 1988, p. 53 y ss. Asimismo, ffr. César Sepúlveda, Estudios sobre Derecho internacional...., op. cit., p. 13 y ss.; y Cançado Trindade, El Derecho internacional de los derechos humanos en el siglo XXI, Santiago, Ed. Jurídica de Chile, 2001, p. 48 y ss., $y$ «Las cláusulas pétreas de la protección internacional del ser humano. El acceso directo de los individuos a la justicia a nivel internacional y la intangibilidad de la jurisdicción obligatoria de los tribunales internacionales de derechos humanos", en AAVV, El sistema interamericano..., op. cit., t. I, p. 7.

15 En el preámbulo de la Carta de las Naciones Unidas se expresa la resolución de «reafirmar la fe en los derechos fundamentales del hombre, en la dignidad de derechos fundamentales del hombre, en la dignidad y el valor de la persona humana, en la igualdad los derechos hombres y mujeres de las naciones grandes y pequeñas"; y en el artículo 1.3 se incluye, entre otros propósitos de las Naciones Unidas, uel desarrollo y estímulo del respeto a los derechos humanos y a las libertades fundamentales de todos, sin hacer distinción por motivo de raza, sexo, idioma o religión".

16 En el preámbulo de la Carta de la Organización de los Estados Americanos (reformada en Buenos Aires, en 1967) éstos se manifiestan por "consolidar en este Continente, dentro del marco de las instituciones democráticas, un régimen de libertad individual y de justicia social, fundado en el respeto de los derechos esenciales del hombre». La misma Carta señala: «Los Estados Americanos proclaman los derechos fundamentales de la persona humana sin hacer distinción de raza, nacionalidad, credo o sexo". Asimismo, cfr., las diversas normas que entrañan derechos de la persona, contenidas en los capítulos VII a IX de este instrumento internacional.

17 Que representa un trascendental jalón en la historia: gran consenso sobre los derechos humanos, prueba de fundamento, reconocimiento y validez. Establece el prin- 
Declaración Americana de los Derechos y Deberes del Hombre (1948, anterior a la universal), la Convención de Roma sobre Derechos Humanos y Libertades Fundamentales (1950), que previó la existencia de una Corte Europea sobre esta materia, los Pactos Internacionales de Derechos Civiles y Políticos y de Derechos Económicos, Sociales y Culturales (1966) ${ }^{18}$ la Convención Americana sobre Derechos Humanos o «Pacto de San José» (1969, que prevé la creación y las atribuciones de la correspondiente Corte Interamericana) y la Carta Africana de los Derechos del Hombre y de los Pueblos (1981) ${ }^{19}$.

El gran conjunto forma el más poderoso escudo protector del ser humano, con doble cobertura, íntimamente comunicada: una pretende abarcar el mundo entero, y por este medio a la humanidad en pleno, un antiguo sueño ecuménico; otra recoge y refuerza la tutela en los planos regionales, con lo que concilia la «idea general" con la "realidad regional", y de esta manera acoge las pretensiones universales y reconoce y respeta las tensiones regionales, mucho más cercanas que aquéllas a las tensiones nacionales, que es preciso advertir y admitir. Lo interesante y decisivo, en todo caso, es que las fronteras nacionales han sido trascendidas precisamente en la materia en que esa trascendencia puede tener la

cipio de un largo proceso, cuyo final se halla distante. Cfr. Bobbio, L'età..., op. cit., pp. $18-24$.

18 Se considera que la Declaración Universal y los Pactos Internacionales integran la "Carta Internacional de los Derechos Humanos". Jorge Montaño, Las Naciones Unidas y el orden mundial 1945-1992, México, Fondo de Cultura Económica, 1992, p. 77, y Yerenit Morgan Sotomayor, "Los derechos humanos en la Organización de las Naciones Unidas», en Revista Mexicana de Politica Exterior, México, nos. 55-56, febrero de 1999, pp. 71-72. En 1946, el Consejo Económico y Social de las Naciones Unidas estableció, mediante resoluciones 5 (1) y 9 (II) de la Comisión de Derechos Humanos y le encomendó inmediatamente la redacción de una Carta Internacional de Derechos Humanos. Cfr. Morgan Sotomayor, ibidem, pp. 70-71.

19 Se trata, en este caso, del instrumento que cimienta un sistema emergente de tutela de los derechos humanos. En éste, conocido también como "Carta de Banjul» (aprobada el 27 de julio de 1981, en Nairobi, Kenia), el Preámbulo reconoce "por una parte, que los derechos fundamentales del ser humano se fundamentan sobre los atributos de la persona humana, lo que justifica su protección internacional; y por la otra parte, que la realidad y el respeto a los derechos del pueblo deben necesariamente garantizar los derechos humanos». La Carta prevé la existencia de una Comisión Africana de Derechos Humanos y de los Pueblos, todavía no del órgano jurisdiccional correspondiente, a la manera europea o americana. 
más penetrante eficacia: los temas jurídicos radicales del ser humano ${ }^{20}$. Así, en ese conjunto imperioso aparece nítidamente la figura del individuo en el escenario del Derecho entero: lo estaba ya en el plano nacional, merced a las Constituciones herederas del humanismo del siglo XVIII; llega a estarlo -para no perder esta posición privilegada- en el Derecho de gentes ${ }^{21}$, aun cuando comparezca, por lo pronto, con una "subjetividad jurídica muy limitada» 22 , y en buena medida figure ahí como lo hizo en los albores del constitucionalismo humanista y redentor: para contener el asedio o el impacto del poder arbitrario. Esta fue, en su hora, la gallarda misión de la Declaración francesa de 1789, expedida -previo debate en la Asamblea- como solitaria y suficiente expresión de un acuerdo político. No fue necesario que precediera o acompañara a la Constitución: "tendría una vida autónoma y además -hay que reconocerlo- gloriosa $»^{23}$.

Aquí, donde una revolución se ha producido, la Carta de las Naciones Unidas encabeza la profesión de fe humanista. «Ha roto -escribió un ilustre internacionalista- con el principio de que un Estado puede tratar a sus súbditos a su arbitrio, sustituyéndolo por el principio nuevo de

20 Sergio López Ayllón señala que la globalidad ha captado el espacio de los derechos humanos. La internacionalización de éstos genera un auténtico Derecho internacional que conforma cuatro sistemas supranacionales, cada uno con vida propia: el global, de las Naciones Unidas, y los regionales de Europa, América y África. Cfr. Las transformaciones del sistema juridico y los significados sociales del Derecho en México. La encrucijada entre tradición y modernidad, México, UNAM, Instituto de Investigaciones Jurídicas, 1997, pp. 74-76; y "Globalización y transición del Estado nacional», en María del Refugio González y Sergio López Ayllón (eds.), Transiciones y diseños institucionales, México, UNAM, Instituto de Investigaciones Jurídicas, 1999, p. 315.

21 Se trata, en fin, de la defensa del ciudadano frente al "Estado delincuente", como lo denomina Ferrajoli, para el caso de que no sea efectivo el Derecho penal y procesal interno. Este es un tema tradicional del internacionalismo. "En teoría, el reconocimiento del carácter fundamental de los derechos vitales de los ciudadanos frente a los Estados equivale, desde el punto de vista externo, a la afirmación de su carácter supra-estatal y, por consiguiente, internacional". Derecho y razón. Teoria del garantismo penal, trad. de Perfecto Andrés Ibán̄ez, Alfonso Ruiz Miguel, Juan Carlos Bayón Mohino, Juan Terradillas Basoco y Rocío Cantarero Bandrés, 3ª. ed., Madrid, Ed. Trotta, 1998, p. 937.

22 Manuel Becerra Ramírez, "Derecho internacional público", en El Derecho en México. Una visión de Conjunto, México, UNAM, Instituto de Investigaciones Jurídicas, 1991 , t. III, p. 1364.

23 Bobbio, L'età..., op. cit., p. 130. 
que la protección de los derechos humanos constituye una cuestión fundamentalmente internacional ${ }^{24}$. Esa Carta y la Declaración Universal se ha escrito también- «transformaron el orden jurídico del mundo, llevándolo del estado de naturaleza al estado civil. Los Estados signatarios quedaron legalmente sujetos a normas fundamentales: el imperativo de la paz y el mantenimiento de los derechos humanos" ${ }^{25}$. Finalmente los derechos humanos han pasado a constituir un valor propio en el Derecho internacional, que incumbe y compromete a éste ${ }^{26}$.

De esto -y de otros notables desarrollos- resulta un nuevo dato de la vida jurídica, que se proyecta sobre el ordenamiento internacional y los órdenes jurídicos nacionales: «hoy día es indiscutible que la materia de los derechos humanos no es un tema perteneciente al dominio reservado de los Estados". En tal sentido se inscribe una vigorosa corriente de opinión ${ }^{27}$. La globalidad -a la que me referiré en el siguiente capítulomilita en la misma dirección. Más aún, la admisión y la protección de los derechos humanos son vistas como puntos de legitimidad ${ }^{28}$ y presti-

24 La Carta contiene «un reconocimiento internacional de principio de los derechos humanos", en pos de la Declaración de $1^{\circ}$ de enero de 1942, en la circunstancia de la Segunda Guerra, en la que las potencias aliadas se comprometían a preservar los derechos humanos y la justicia en los propios países de los individuos y en otros territorios (in their own lands as well as in other lands). Alfred Verdross, Derecho internacional puiblico, trad. de Antonio Truyol y Sierra, Madrid, Aguilar, 1957, pp. 442-443.

25 «Desde aquel momento -sostiene Luigi Ferrajoli- la soberanía se tornó un concepto inconsistente desde el punto de vista lógico [...] la santificación de los derechos humanos en la Declaración de 1948 y los tratados de 1966 hizo de ellos no sólo derechos constitucionales, sino supraestatales, transformándolos en límites externos y no simplemente internos de los poderes de los Estados». "Más allá de la soberanía y la ciudadanía: un constitucionalismo global", en Miguel Carbonell y Rodolfo Vázquez (comps.), Estado constitucional y globalizacion, op. cit., p. 317.

26 Cfr. Germán F. Bidart Campos, Teoria general de los derechos humanos, México, UNAM, Instituto de Investigaciones Jurídicas, 1989, p. 434 y ss.

27 Aquella "afirmación es compartida prácticamente por la unanimidad de la doctrina y por la jurisprudencia de la Corte Internacional de Justicia, de la Corte Europea de Derechos Humanos y de la Corte Interamericana de Derechos Humanosm. Héctor Gros Espiell, "El llamado "derecho de injerencia humanitaria" en un mundo interdependiente", en Modesto Seara Vázquez (comp.), Las Naciones Unidas a los cincuenta años, $1^{\text {a }}$ ed., $1^{\text {a }}$ reimp., México, Fondo de Cultura Económica, 1996, pp. 210-211.

28 López Ayllón señala que hoy día, bajo la globalización, «una parte significativa de la construcción de la legitimidad de un Estado encucntra sus bases en el respeto a estos derechos. Estos se han convertido así en un elemento legitimador de las relacio- 
gio. He aquí una nueva proyección de Jano, rostro dual, espada de doble filo: la vertiente luminosa se significa por la preocupación genuina cifrada en los derechos humanos; la sombría, por el uso de éstos -o de esta bandera y este discurso, mejor dicho- con fines y métodos muy distantes de aquélla.

La índole expansiva de los derechos humanos -del núcleo duro, irreductible ${ }^{29}$, al florecimiento en número y calidad, a través de sendos círculos concéntricos- viene del origen mismo de esos derechos, que ha sido materia de intenso debate ${ }^{30}$ y prosigue hoy día, no exenta de pro-

nes políticas y sociales, tanto desde el punto de vista interno como del externo, y ha sido inevitable su transformación en un elemento de política internacional en el que intervienen no sólo los Estados, sino una variedad de organizaciones intergubernamentales y no gubernamentales, constituidas frecuentemente en sedes que desafían cualquier intento de control territorial». "Globalización y transición...", en María del Refugio González y Sergio López Ayllón (eds.), Transiciones y diseños..., p. 316. Adelante volveré sobre el papel destacado de las organizaciones no gubernamentales, a propósito de su actuación en la jurisdicción interamericana. Conviene subrayar desde ahora que aunque no todas actúan en el campo de los derechos humanos, hay muchas que operan en este ámbito. Refiriéndose a aquéllas, en general, Hugo Concha informa que hace dos décadas eran sólo un centenar (en México). En 1995 ese número había crecido espectacularmente: llegaban a 1,300 según la Secretaría de Gobernación, o a 10,000, según el grupo San Ángel. «La legitimidad del Estado mexicano», en María del Refugio González y Sergio López Ayllón (eds.), Transiciones y diseños..., op. cit., pp. 391-392.

29 Ante todo, pero no exclusivamente, los derechos reconocidos en los instrumentos "germinales» de los derechos humanos. La sección 1 de The Virginia Declaration of Rights, del 12 de junio de 1776, proclama uque todos los hombres son por naturaleza igualmente libres e independientes y tienen ciertos derechos innatos, de los cuales, cuando entran en estado de sociedad, no pueden, por ningún pacto, privar o desposeer a su posteridad; a saber, el goce de la vida y de la libertad, con los medios para adquirir y poseer la propiedad, y buscar y conseguir la felicidad y la seguridad". La Declaración de Independencia de los Estados Unidos de América, del 4 de julio de 1776, sostuvo, entre otras verdades "evidentes por sí mismas", que "todos los hombres son creados iguales; que están dotados por su creador de ciertos derechos inalienables; que, entre éstos, están la vida, la libertad y la búsqueda de la felicidad [...]”. A su vez, la Déclaration des Droits de l'Homme et du Citoyen, del 20-26 de agosto de 1789, señala que ulos hombres nacen y viven libres e iguales en derecho [...]" (artículo $1^{\circ}$ ), y que los derechos naturales e imprescriptibles del hombre «son la libertad, la propiedad, la seguridad y la resistencia a la opresión" (artículo $2^{\circ}$ ).

30 Recuérdese la vigorosa polémica entre el alemán Jellinek y el francés Boutmy. Aquél diría que la Declaración francesa no tiene su raíz en la doctrina contractualista de Rousseau, sino en las declaraciones americanas, y que «el primer Estado que ha 
blemas $^{31}$. Obviamente, no se pretende que todos los derechos sean calificados como humanos, en el sentido que ahora interesa ${ }^{32}$, aunque es evidente que sólo el ser humano es titular de derechos de este carácter sin perjuicio de la atribución de facultades a personas morales, que luego examinaré-; de lo que se trata, en fin de cuentas, es de preservar derechos fundamentales, esenciales para la vida y para cierta calidad de vida $^{33}$.

producido una Declaración de Derechos en el pleno sentido de la palabra, fue el de Virginia". George Jellinek, La declaración de los derechos del hombre y del ciudadano, trad. de Adolfo Posada, México, UNAM, Instituto de Investigaciones Jurídicas, 2000, pp. 85-92. Bobbio señala que la Revolución americana abrió la puerta a las revoluciones de Europa. La francesa «ha constituido, durante casi dos siglos, el modelo ideal para todos los que luchan por su propia emancipación y por la liberación de su propio pueblo. Los principios de 1789 constituyeron para bien o para mal, un punto de referencia obligado para los amigos y para los enemigos de la libertad, invocados por aquéllos, execrados por éstos». Bobbio, L'età..., op. cit., pp. 95 y 100.

$31 \mathrm{La}$ «ampliación de la noción de derechos humanos, no puede darse sin generar varias dificultades. Y ello es así porque a fuerza de querer ampliar y ensanchar el concepto, este mismo corre el grave riesgo de perder su consistencia real, y que en lugar de reforzar la protección de las libertades fundamentales, corra el peligro de debilitarlas y menguar su alcance jurídico». Alonso Gómez Robledo Verduzco, Derechos humanos en el sistema interamericano, México, UNAM, Instituto de Investigaciones Jurídicas/Ed. Porrúa, 2000, p. 284.

32 Podríamos hablar mejor de derechos fundamentales: los esenciales, los nucleares e irreductibles, los intransigibles e indeclinables conforme al concepto que prevalece en cierto tiempo y espacio, conforme a determinada cultura, según la exigencia radical del nombre a la luz de su dignidad inviolable y de las exigencias de su desarrollo. Para Luigi Ferrajoli «los derechos fundamentales, en contraposición a todas las demás situaciones jurídicas (son) aquellos derechos cuya garantía es igualmente necesaria para satisfacer el valor de las personas y para realizar su igualdad". Derecho y razón..., op. cit., p. 908.

33 En efecto, «no nos referimos a todos los derechos de que pueda ser titular un ser humano [...] Esta expresión (derechos humanos) se ha reservado para ciertos derechos básicos o elementales, que son inherentes a toda persona, y que derivan únicamente de su condición de ser humano". Se resalta, pues, "el carácter histórico y valorativo de los derechos humanos, sugiriendo que son el producto inacabado de las luchas sociales, $y$ que reflejan el tipo de sociedad que queremos"; por ende, «tienen un carácter fluido y dinámico, que corresponde a las relaciones de poder y a las ideas prevalecientes en el seno de la sociedad en que aquellos adquieren vigenciam. Héctor Faúndez Ledesma, El sistema interamericano de protección de los derechos humanos. Aspectos institucionales y procesales, San José, Costa Rica, Instituto Interamericano de Derechos Humanos, 1996, pp. 21-22. 
Ahora bien, aquí nos hallamos ante un concepto histórico, necesariamente movedizo: no se retrae, se expande. Los derechos humanos «no nacen todos de una vez. Nacen cuando deben y pueden nacer»" Lo que pudo parecer suficiente para los americanos emergentes que se alejaban de la corona inglesa o para los revolucionarios que recorrían las calles de París en 1789 - iy vaya que entonces era y parecía suficiente el apretado haz de derechos que contuvo la Déclaration de aquel año!-, testigos de una formulación laboriosa y difícil ${ }^{35}$, ya no lo es para quienes hoy transitamos las calles de las grandes concentraciones urbanas del tercer milenio. Cada contingente de libertades y derechos representa un momento en el camino ascendente de la justicia y de libertad. hubo, sin embargo, un episodio formidable en este trayecto perseverante: la Revolución francesa, con la que «ingresa a la imaginación de los hombres la idea de un suceso político extraordinario que al romper la continuidad del curso histórico, marca el final de una etapa y el principio de otra» ${ }^{36}$.

Ese carácter dinámico, expansivo, de los derechos fundamentales se manifiesta en lo que algunos tratadistas denominan, gráficamente, "generaciones de derechos humanos» ${ }^{37}$, un concepto que no todos aceptan de buen grado ${ }^{38}$. Estas son, en rigor, la expresión de diversas generacio-

34 Los derechos del hombre son derechos históricos, inmersos en una circunstancia caracterizada por la lucha para defender nuevas libertades contra viejos poderes. Bobbio, L'età..., op. cit., pp. XIII, XV y 9 y ss.

35 Se ha escrito - a la vista del arduo proceso de elaboración del documento, erizado de tensiones- que, «sorprende[...] la contradicción que hay entre el éxito histórico del texto y las difíciles condiciones de su producción, su carácter inacabado». Christine Fauré, Las declaraciones de los derechos del hombre de 1789, trad. de Diana Sánchez y José Luis Núñez Herrejón, $1^{a}$. ed., 2a reimp., México, Comisión Nacional de Derechos Humanos/ Fondo de Cultura Económica, 1999, p. 15. Igualmente, sobre este proceso, cfr. Carlos Sánchez Viamonte, Los derechos del hombre en la Revolución Francesa, México, UNAM, Facultad de Derecho, 1956.

36 Bobbio, L'età..., op. cit., p. 120.

37 Cfr. Bidart Campos, Teoria general..., op. cit., pp. 195 y ss. Cfr. los componentes del sistema de derechos humanos, como dato actual de las aportaciones "generacionales", y su posible síntesis en un derecho individual al desarrollo, que abarca libertad, justicia y bienestar, en García Ramírez, Los derechos humanos y el Derecho penal, op. cit., pp. 172-173. Cfr, asimismo, mi trabajo «La jurisdicción americana sobre derechos humanos. Actualidad y perspectivas», en García Ramírez, Estudios jurídicos, México, UNAM, Instituto de Investigaciones Jurídicas, 2000, pp. 280-281.

38 Así, Cançado Trindade la impugna: es una teoría «reminiscente de la triada libertélégalitélfraternité de los compatriotas de Voltaire (con posible mérito pedagógico 
nes revolucionarias que alimentan la expansión y el enriquecimiento de aquellos derechos, o dicho de otra forma, generaciones de exigencias emergentes y de libertades, facultades y prerrogativas vinculadas con éstos. Es lo que va de las reivindicaciones de los revolucionarios norteamericanos y franceses, en el ocaso del siglo XVIII ${ }^{39}$, a las reclamaciones de los revolucionarios mexicanos, estampadas en la Constitución de Querétaro, ${ }^{40}$ apenas iniciado el siglo XX -que aportarían al mundo la herencia de los derechos sociales ${ }^{41}$, tema de enorme importancia en el

o quizás literario): dicha construcción teórica ha ejercido y sigue ejerciendo una cierta fascinación en nuestros círculos jurídicos, reflejada en la bibliografía especializada latinoamericana, a pesar de (ser) históricamente inexacta y jurídicamente infundada". «Reflexiones sobre el futuro del sistema interamericano de protección de los derechos humanos», en Juan E. Méndez y Francisco Cox (eds.), El futuro del sistema interamericano de protección de los derechos humanos, San José, Costa Rica, Instituto Interamericano de Derechos Humanos, 1998, p. 583.

39 En aquéllas hubo anticipaciones de carácter «social». Al calor del movimiento revolucionario francés, florecieron algunas declaraciones precursoras de los que serían, un siglo más tarde, «derechos sociales constitucionales». Así, a propósito del derecho a la instrucción pública, en los términos del Título Primero de la Constitución del 3 de septiembre de 1791; la instrucción elemental, que debe proveer la sociedad, conforme al artículo $23^{\circ}$ del proyecto girondino presentado el 15 y el 16 de febrero de 1793 , y a los artículos $21^{\circ}$ y $22^{\circ}$ de la Constitución del 24 de junio de 1793 (o del año I), acerca de esta misma prerrogativa y del derecho al apoyo social para la subsistencia de los menos favorecidos, sea mediante el acceso al trabajo, sea mediante la asistencia a quienes no se hallan en condiciones de trabajar. Los derechos sociales, bajo la forma de instituciones de instrucción pública y de provisiones en favor del trabajo, «hicieron su primera aparición" en la Constitución francesa de 1791 y en la Declaración de Derechos de junio de 1793. Cfr. Bobbio, L'età..., op. cit., pp. 258-259.

40 Sobre este punto reviste particular importancia la obra del diputado constituyente Pastor Rouaix, Génesis de los articulos $27^{\circ}$ y $123^{\circ}$ de la Constitución Politica de 1917, 2a . cd., México, Instituto Nacional de Estudios Históricos de la Revolución Mexicana, 1959. Los diputados renovadores integraron lo que el propio Rouaix denominaría el núcleo fundador u original, que redactaría el proyecto de artículo $123^{\circ}$. Cfr . Varios autores, La Constitución Mexicana de 1917. Ideólogos, el nuicleo fundador y otros constituyentes, México, UNAM, Instituto de Investigaciones Jurídicas, 1990.

41 Un amplio examen de csta materia, en Jorge Sayeg Helú, El constitucionalismo social mexicano. La integración constitucional de México (1808-1988), $1^{\text {a }}$. ed., México, Fondo de Cultura Económica, 1991. De esto me he ocupado en diversos trabajos, entre ellos "Raíz y horizonte de los derechos "sociales" en la Constitución mexicana", en Liber Amicontum Héctor Fix-Zamudio, San José, Costa Rica, Secretaría de la Corte Interamericana de Derechos Humanos, 1998, p. 77 y ss., así como en Estudios juridicos, op. cit., p. 15 y ss. Sobre la naturaleza y objetivos de los derechos sociales, cfr. Luis 
casi centenario examen de la Constitución Mexicana ${ }^{42}$-, y de aquí al final de esa centuria, con la generalización de otras proclamaciones: los derechos de solidaridad. Dicho de otra manera, es lo que va de los «derechos de libertad (o "derechos de") (que) aseguran la igualdad formal o política", a los "derechos sociales (o "derechos a") que posibilitan la igualdad sustancial o socialn ${ }^{43}$.

En fin de cuentas el modelo tradicional -largamente anhelado y generosamente celebrado- que confió en los derechos fundamentales primigenios y la división del poder, gran esperanza del pensamiento liberal, «no sólo no promovió el establecimiento de una sociedad armónica y estable, sino que exacerbó la desigualdad, la explotación y el descontento social» ${ }^{44}$. Por ello, a los derechos humanos - del cuño tradicio-

Prieto Sanchís, «Los derechos sociales y el principio de igualdad sustancial», en Miguel Carbonell, Juan A. Cruz Parcero y Rodolfo Vázquez (comps), Derechos sociales y derechos de las minorias, México, UNAM, Instituto de Investigaciones Jurídicas, 2000, p. 15 y ss. Cfr., asimismo, Alfonso Noriega Cantú, La naturaleza de las garantías individuales en la Constitución de 1917, México, UNAM, Coordinación de Humanidades, 1967, p. 70 y ss. y 112 y ss.; Rodolfo Lara Ponte, Los derechos humanos en el constitucionalismo mexicano, México, H. Cámara de Diputados, LV Legislatura/UNAM, Instituto de Investigaciones Jurídicas, 1993, p. 127 y ss.; Mariano Palacios Alcocer, El régimen de garantias sociales en el constitucionalismo mexicano, México, UNAM, Instituto de Investigaciones Jurídicas, 1995; De la Madrid, «La Constitución y sus principios fundamentales", en Diego Valadés y Gutiérrez Rivas (coords.), Economía y Constitución. Memoria del IV Congreso Nacional de Derecho Constitucional, México, UNAM, Instituto de Investigaciones Jurídicas, 2001, p. 44 y ss, y Salvador Valencia Carmona, Derecho constitucional mexicano a fin de siglo, México, Ed. Porrúa, 1995, p. 191 y ss.

42 Cfr. García Ramírez, "Raíz y horizonte de los derechos sociales en la Constitución mexicana», en Estudios juridicos, op. cit., p. 52 y ss. José Ramón Cossío reconoce que los derechos sociales fueron «lo nuevo de nuestro texton; y plantea interesantes consideraciones sobre los efectos de la representación Constitucional dominante en los derechos sociales. Cfr. Cambio social y cambio jurídico, México, Instituto Tecnológico Autónomo de México, Miguel Ángel Porrúa, 2001, p. 122 y ss.

43 Unos "tutelan las diferencias, para las que postulan la tolerancia; "los otros" remueven o compensan las desigualdades que postulan, como intolerables. Los derechos del primer tipo son derechos a la diferencia, es decir, a ser uno mismo y a seguir siendo personas diferentes de las demás; los del segundo son derechos a la compensación de las desigualdades y, por ello, a llegar a ser personas iguales a las demás en las condiciones mínimas de vida y supervivencia. En el primer caso, la diversidad es un valor a garantizar; en el segundo, un desvalor al que hay que oponerse». Ferrajoli, Derecho y razón... op. cit., p. 907.

44 Concha Cantú, «La legitimidad del Estado...», en María del Refugio González y Sergio López Ayllón (eds.), Transiciones y diseños..., op. cit., p. 359. 
nal- se agregaron los derechos sociales, "entendidos, al menos en un primer momento, como protecciones dirigidas de manera directa a las clases más dañadas por las relaciones económicas» ${ }^{45}$.

Es así que se ha constituido paulatinamente -0 se está constituyendo, con notable adelanto- un corpus juris universal. La humanidad avanza hacia lo que podría denominarse una "Constitución Universal», que no será solamente la estructura de la comunidad (el cuerpo), sino también el fin hacia el que ésta se dirige y la forma de alcanzarlo (el alma): derechos humanos y democracia.

Tras las declaraciones, que por sí mismas pudieran carecer de eficacia real -o al menos de exigibilidad-, acuden los instrumentos y los procedimientos, esto es, las garantías de los derechos, que propuso el artículo $16^{\circ}$ de la Declaración francesa de $1789^{46}$ : una suma de medios, al alcance del individuo concreto -aunque el acceso a esta vertiente de la justicia se halla todavía sembrado de obstáculos-, que le permitan recuperar sus derechos negados o violentados, evitar la probable vulneración o alcanzar debido y puntual resarcimiento una vez que la infracción se ha cometido $^{47}$, incluso cuando las condiciones prevalecientes, en forma pasajera, llevan a suspender el ejercicio de ciertos derechos.

La fijación de las hipótesis de suspensión de derechos suele ser insuficiente $u$ oscura ${ }^{48}$. La inconsecuencia entre las medidas adoptadas por

45 Ibidem, p. 362.

46 Artículo $16^{\circ}$ : "Toda sociedad en la que no está asegurada la garantía de los derechos, ni determinada la separación de los poderes, no tiene Constitución»; digamos: no dispone de un Estado de Derecho, en el profundo sentido jurídico y ético de esta expresión.

47 Ferrajoli destaca la importancia que revisten las garantías de los derechos fundamentales. Subraya dos principios: 1) de legalidad: es preciso que esos derechos no queden al arbitrio de las autoridades, y por ello es indispensable "que las leyes provean únicamente sus presupuestos vinculantes e identifiquen con claridad sus órganos y procedimientos»; y 2) de jurisdiccionalidad: es menester que los derechos "sean todos justiciables, es decir, accionables en juicio frente a los sujetos responsables de su violación, sea por comisión, sea por omisión». Derecho y razón..., op. cit., p. 917.

48 Diego Valadés advierte: "Todas las constituciones latinoamericanas precisan los casos en que procede declarar el estado de excepción; pero ninguna escapa, aunque parezca haber intentos en ese sentido, a la extrema vaguedad conceptual». Por ello, en el fondo, la "principal" causa «es la voluntad de los detentadores del poder. Volvemos, así, a la vieja razón de Estado". La dictadura constitucional en América Latina, México, UNAM, Instituto de Investigaciones Jurídicas, 1974, p. 47. 
la autoridad que dispone la suspensión y el problema que se pretende afrontar de esta manera, implica «establecer una dictadura con el pretexto de una suspensión de garantías" ${ }^{49}$ precisamente para preservar la vida y la marcha de la sociedad o la continuidad del Estado de Derecho ${ }^{50}$, posibilidad empleada con prudencia o con desmesura, hasta introducir, en este último caso, lo que se ha denominado, expresivamente, una "dictadura constitucional». ${ }^{51}$

Por todo ello, las jurisdicciones sobre derechos humanos, nacionales e internacionales, que sirven a esos fines indispensables, caracterizan la actual etapa constructiva de la tutela al ser humano: una etapa desarrollada a lo largo de la segunda mitad del siglo XX, con la que hemos iniciado el $\mathrm{XXI}^{52}$. Es así que, una vez resuelto, al través de cierta convergencia internacional, el fundamento de los derechos humanos, -una

49 Ulises Schmill Ordóñez, El sistema de la Constitución mexicana, México, Manuel Porrúa, 1971, p. 172.

50 En tales casos, sin embargo, subsisten intocables determinadas garantías jurisdiccionales, como lo previene con puntualidad el artículo $27^{\circ}$ de la Convención Americana (no así el correlativo artículo $29^{\circ}$ de la Constitución mexicana, cuyo sistema, por lo tanto, debe ser complementado y acotado por la norma de la Convención Americana) y lo ha expresado la Corte Interamericana en sus Opiniones Consultivas 8 , de 30 de enero de 1987, y 9 de 6 de octubre del mismo año. Sobre esta materia, cfr., Leandro Despouy, Los derechos humanos y los estados de excepción, México, UNAM, Instituto de Investigaciones Jurídicas, 1999. Sobre garantías suspendibles en los ordenamientos constitucionales latinoamericanos, $c f r$. Valadés, La dictadura..., op. cit., p. 91 y ss; y sobre el caso de México, ibidem, p. 114 y ss.

$51 \mathrm{El}$ uso inmoderado de la suspensión de garantías, estado de excepción, estado de sitio, etcétera, con «sustento» en normas constitucionales -más o menos aplicadas a la hipótesis que determina la alteración-ha dado lugar a lo que algunos autores llaman dictadura constitucional, que "ha representado uno de los más caros desiderata del Estado latinoamericano -escribe Diego Valadés-. Este ha tenido la habilidad, quizá, de practicarla en nombre de una supuesta democracia. Ibidem, p. 158.

52 En un balance sobre el desarrollo en materia de derechos humanos a partir de la Declaración Universal (1948), Antônio Cançado Trindade resume: “Al volver los ojos tanto hacia cl pasado reciente como hacia el presente, nos damos cucnta de que efectivarnente hubo, en estas cinco décadas de experiencia acumulada en esta área, un claro progreso, sobre todo en la jurisdiccionalización de la protección internacional de los dercchos humanos". El Derecho internacional de los derechos humanos en el siglo XXI, Santiago, Ed. Jurídica de Chile, 2001, p. 379; en el mismo sentido, de aquel autor, "Prólogo" a AAVV, El sistema interamericano.., op. cit., t. I, p. XXIII. 
cuestión filosófica- se marcha adelante en la solución del otro problema que aquí se suscita: su tutela efectiva-una cuestión política- ${ }^{53}$.

En rigor, la jurisdiccionalización de los conflictos internacionales desarrollada a imagen y semejanza de su contrapartida nacional-, en el amplio espacio de lo que se pudiera denominar la «jurisdicción internacional plena», es el moderno sucedáneo de la fuerza, que batalla por sus fueros cada vez que se rehusa a entregar a los órganos de la justicia las contiendas que ésta puede y debe resolver ${ }^{54} 55$.

Este conjunto magnífico de libertades, expectativas y garantías ha dejado de ser materia exclusiva de alguna competencia, reducida a los límites de un territorio y de una jurisdicción. Hoy interesa al mundo entero, que cultiva los derechos -o debiera hacerlo: también en esta luna hay una cara luminosa y otra sombría- tanto a través de medios nacionales como de instrumentos internacionales ${ }^{56}$. Desde luego, la jurisdic-

53 Cfr. Bobbio, «Presente y futuro de los derechos humanos», en Anuario de Derechos Humanos 1981, Madrid, Universidad Complutense, Facultad de Derecho, Instituto de Derechos Humanos, 1982, p. 10; El problema de la guerra y las vías de la paz, trad. de Jorge Binaghi, España, Ed. Gedisa, 1982, p. 130; Bobbio, L'età..., op. cit., p. 16.

54 Hans Kelsen, que coteja el desenvolvimiento equivalente entre órganos nacionales e internacionales, observa que "la evolución natural de los hechos tiende a una judicatura internacional. El primer paso hacia una paz duradera debe consistir en el establecimiento de una comunidad internacional, cuyos miembros estén obligados a someter todas las disputas que surjan entre ellos a un tribunal internacional permanente y a respetar las decisiones de esta autoridad". Derecho y paz en las relaciones internacionales, trad. de Florencio Acosta, México, Fondo de Cultura Económica, 1943, p. 180 y ss.

55 Henry Kissinger denuncia: «En menos de una década, ha surgido un movimiento que carece de precedente y que consiste en someter la política internacional a procesos judiciales». Previene que esto puede llegar a "extremos que ponen en riesgo de sustituir la tiranía de los gobiernos por la de los jueces; la historia nos enseña que la dictadura de los virtuosos ha lievado a menudo a inquisiciones y cacerías de brujas". "Las trampas de la jurisdicción internacional" (artículo que constituye una adaptación del libro de aquel autor, Does America need a foreign policy? Toward a diplomacy for the 21st. Century), en Foreign Affairs (en español), México, vol. I, num. 3, otoño-invierno 2001, p. 87. Kissenger impugna particularmente la Corte Penal Internacional. Réplicas de Michael Mandelboum, "La conciencia de un conservador. Los peligros del dogmatismo en la política exterior estadounidensen, en ibidem, p. 264 y ss.; y Kenneth Roth, "El debate de la jurisdicción universal”, en ibidem, p. 259 y ss.

56 «En la actualidad se conceptúa que los derechos del hombre constituyen una materia regulada por el derecho interno y por el internacional y que el Derecho de los Estados y el derecho internacional, universal o regional, deben necesariamente coexis- 
ción nacional - como el Derecho nacional en su conjunto-suele tener y debe poseer carácter preferente; la internacional es subsidiaria. De todo ello proviene el estatuto del hombre contemporáneo, un tema del que me ocuparé adelante.

En esta etapa se recupera un antiguo sueño, que inicia su afirmación en la tierra: aparece el ser humano en el contexto universal, un citoyen $d u$ monde, que no deja de ser -ni conviene que esto ocurra- ciudadano de su propia ciudad. El hombre adquiere -como se ha escrito- un status mundialis fundamental ${ }^{57}$.

\section{La circunstancia de los derechos humanos}

La efectiva vigencia de los derechos humanos tiene que ver, sobre todo, con «la tierra en la que se siembren» ${ }^{58}$. También ellos son la suma de lo que entrañan y de la circunstancia en la que aparecen y prosperan. La naturaleza de ésta -que es fundamento, escudo y contexto- puede extraerse de los dos términos con que caracterizamos el dinámico concepto de los derechos humanos, y son su fuerte razón y sustento. Por una parte, la dignidad humana; por la otra, el Derecho y los derechos. Así, el reconocimiento de la dignidad del ser humano, que se halla en la raíz de los derechos humanos $-\mathrm{y}$ en tal virtud concilia las corrientes iusnaturalistas y positivistas- induce al culto de ésta -que es la idea motriz- y al cultivo de sus implicaciones -que es la práctica, a partir de aquélla-, un cultivo que se discurre en el cauce propuesto por Ulpiano:

tir en la promoción, garantía y defensa de los derechos de la persona humana». Héctor Gros Espiell, «Universalismo y regionalismo en la protección internacional de los derechos humanos", en AAVV, Los tratados sobre derechos humanos y la legislación mexicana, México, UNAM, Instituto de Investigaciones Jurídicas, 1981, p. 8.

57 Cfr. Peter Häberle, El Estado constitucional, trad. de Héctor Fix-Fierro, México, UNAM, Instituto de Investigaciones Jurídicas, 2001, p. 182 y ss.

58 Es aplicable la reflexión de Picro Calamandrei: «El verdadero secreto para la salvación de los regímenes democráticos radica en la circunstancia de que para hacer vivir una democracia no es suficiente la razón codificada por los preceptos de una Constitución democrática, sino que se requiere que detrás de la ley fundamental se encuentre la laboriosa presencia de las costumbres democráticas con las que se pretenda y se sepa traducirla, día a día, en una concreta, razonada y razonable realidad". Proceso y democracia, trad. de Héctor Fix-Zamudio, Buenos Aires, EJEA, 1960, p. 56. 
constans et perpetua voluntas. Voluntas política y social: aquélla, como voluntad del Estado; ésta, como determinación de la sociedad.

Por otra parte, la vitalidad y efectividad de los derechos humanos requieren -en lo que toca a la segunda referencia del concepto- el culto del Derecho -que es, en este orden, la idea- y después, con este cimiento, el cultivo. Un cultivo en el que vuelve a volcarse la voluntad del Estado y de la sociedad, asociada a la enérgica determinación del individuo $^{59}$. Es aquí que viene al caso la lucha por el derecho, para citar el título de la famosa obra de Rodolfo Ihering: por el Derecho de todos, el orden jurídico objetivo, que encarna en el Estado de Derecho, y por el derecho de cada uno, el derecho subjetivo, sin el cual aquél permanecería inerte y vacío, como continente exento de contenido ${ }^{60}$.

Estos conceptos pueden asociarse a la estupenda convicción y disposición que contiene el artículo $1^{\circ}$ de la Ley Fundamental de la República Federal Alemana: «La desigualdad de la persona humana es sagrada. Todos los agentes del poder público tienen la obligación absoluta de respetarla y de protegerla. El pueblo alemán reconoce, pues, la existencia de derechos humanos inviolables e inalienables, como base de toda comunidad humana, de la paz y de la justicia en el mundo». Nos hallamos, pues, como se ha escrito, ante un Estado constitucional en cuya "premisa antropológico-cultural» figuran los derechos fundamentales. La Constitución se eleva sobre una concepción antropocéntrica, que se manifiesta tanto en las leyes supremas tradicionales como en las de cuño más reciente: en éstas, la función de los textos se encuentra plenamente al servicio del ser humano, de su dignidad, libertad e igualdad ${ }^{61}$.

Se podría afirmar que el propósito perseguido en este campo es la efectiva vigencia del principio de legalidad, la rule of law, el Estado de Derecho: que el poder se subordine a la ley, el gobernante a la norma,

59 Cfr. García Ramírez, Los derechos humanos y el Derecho penal, op. cit., pp. 175176.

60 Cf: La lucha por el Derecho, trad. de Luis M. de Cádiz, 2a ed., Buenos Aires, Ed. Atlántida, 1954, pp. 87-89.

61 Cfr. Häberle, El Estado..., op. cit., pp. 3 y 115 . Bidart Campos subraya que «de la dignidad humana se desprenden todos los derechos, en cuanto son necesarios para que el hombre desarrolle su personalidad integralmente». El «derecho a ser hombre es el derecho que engloba a todos los demás en el derecho a ser reconocido y a vivir en y con la dignidad propia de la persona humana", Teoría general... op. cit., p. 88. 
para cumplir el ideal platónico y aristotélico ${ }^{62}$. Ahora bien, al hablar de legalidad no solamente nos remitimos a la existencia de un ordenamiento que formalmente reúna las características de una ley, sino entendemos que ese ordenamiento debe merecer igualmente, desde una perspectiva sustancial -que no naufrague en las apariencias, engañosas a menudo-, la calificación de ley conforme a los patrones -o estándares, se suele decir- de una sociedad democrática. La Corte Interamericana de Derechos Humanos -a la que en lo sucesivo identificaré también como la Corte o $\mathrm{CIDH}$ - se ha ocupado en este asunto ${ }^{63}$.

62 Está próximo a su ruina «todo Estado en que la ley carece de fuerza y está sometida a los que gobiernan; y por el contrario, dondequiera que la ley es la única soberana y donde los magistrados son sus primeros súbditos, veo afianzada la salud pública con el cortejo de todos los bienes que los dioses han derramado siempre sobre los Estados». Platón, Las leyes, $3^{a}$. ed., México, Ed. Porrúa, 1979, p. 82. Es necesario que las leyes rectamente establecidas sean soberanas, mientras que las gobernantes, trátese de uno o de más, deben serlo sólo en materias en que es imposible a las leyes expresarse con exactitud"; es preferible "que gobierne la ley antes que uno solo de los ciudadanos; y aún en el caso de que fuera mejor el gobierno de algunos, habría que constituir a éstos en guardianes de la ley y subordinados a ella». El gobierno de un hombre tiene "un elemento de impulso animal [...] la concupiscencia, y el mismo apetito generoso extravía a los gobernantes y a los mejores entre los hombres. La ley es [...] la razón sin apetiton. Aristóteles, Política, trad. de Antonio Gómez Robledo, 9a ed., México, Ed. Porrúa, 1981, pp. 209 y 217. Cfr., igualmente, Bobbio, «Gobierno de los hombres o gobierno de las leyes?», en El futuro de la democracia, trad. de José F. Fernández Santillán, 9a ed., México, Fondo de Cultura Económica, 1996, p. 167 y ss.

63 Sostuvo la Corte en su jurisprudencia consultiva, y lo ha reiterado en la contenciosa, que «no es posible interpretar la expresión leyes, utilizada en el artículo $30^{\circ}$ (de la Convención Americana sobre Derechos Humanos), como sinónimo de cualquier norma jurídica, pues ello equivaldría a admitir que los derechos fundamentales pueden ser restringidos por la sola determinación del poder público, sin otra limitación formal que la de consagrar tales restricciones en disposiciones de carácter general. Tal interpretación conduciría a desconocer límites que el derecho constitucional democrático ha establecido desde que, en el derecho interno, se proclamó la garantía de los derechos fundamentales de la persona; y no se compadecería con el Preámbulo de la Convención Americana, según la cual "los derechos esenciales del hombre [...] tienen como fundamento los atributos de la persona humana, razón por la cual justifican una protección internacional, de naturaleza convencional coadyuvante o complementaria de la que ofrece el derecho interno de los Estados amcricanos". Se dice en seguida: "La expresión leyes, en el marco de la protección a los derechos humanos, carecería de sentido si con ella no se aludicra a la idea de que la sola determinación del poder público no basta para restringir tales derechos. Lo contrario cquivaldría a reconocer una virtualidad absoluta a los poderes de los gobernantes frente a los gobernados. En 
En la historia reciente de los derechos humanos -cuya historia total es, en cierto modo, relativamente reciente: sólo a partir de la insurgencia norteamericana y de la Revolución Francesa- han aparecido nubes adversas, que militan contra ellos bajo diversas banderas, dotadas de poder persuasivo y capacidad de convocatoria. Algunos de estos escollos, en cuyas raíces hay una rara combinación de ignorancia y autoritarismo, se formulan como dilemas exigentes: el ser humano o la sociedad, el ser humano o el Estado, los derechos humanos o la seguridad pública, la soberanía o las jurisdicciones internacionales ${ }^{64}$. Se querría que cada término eliminara al otro, y de esta manera se pretende animar a la opinión pública en una cruzada contra los derechos humanos. Evidentemente, se ignora o se quiere olvidar que sociedad y Estado toman su sentido del ser humano, al que sirven, no del que se sirven; que la seguridad pública es producto del respeto a los derechos humanos y que ella misma es un derecho que reclaman los individuos; que la decisión soberana de las naciones, operando en forma convencida y progresiva, ha instituido las jurisdicciones internacionales a las que los Estados se someten ${ }^{65}$.

En el ancho campo de la tutela internacional de los derechos humanos abundan, por otro lado, las paradojas. Del mismo modo que la

cambio, el vocablo leyes cobra todo su sentido lógico e histórico si se le considera como una exigencia de la necesaria limitación a la interferencia del poder público en la esfera de los derechos y libertades de la persona humana». Prosigue: "Asimismo, la Convención no se limita a exigir la existencia de una ley para que sean jurídicamente lícitas las restricciones al goce y ejercicio de los derechos y libertades, sino que requiere que las leyes se dicten por razones de interés general y con el propósito para el cual han sido establecidas». CIDH, La expresión "leyes» en el artículo $30^{\circ}$ de la Convención Americana sobre Derechos Humanos. Opinión Consultiva OC-6/86 del 9 de mayo de 1986 Serie A No. 6, párrs. 26-28.

64 Ciertas "obsesiones» acerca de la seguridad nacional, el progreso, la incapacidad material de algunos Estados, entre otros argumentos, han opuesto obstáculos a la protección cficaz de los derechos humanos y a la sanción de las violaciones cometidas en este ámbito. Cfr. César Sepúlveda, El Derecho de gentes y la organización internacional en los umbrales del siglo XXI, $1^{\text {a }}$. ed., $1^{\text {a }}$. reimp. México, UNAM, Facultad de Derecho/ Fondo de Cultura Económica, 1997, p. 194.

$65 \mathrm{Al}$ referirse a las aportaciones de la II Conferencia Mundial de Derechos Humanos (Viena, junio de 1993), Cançado Trindade hace ver cómo aquélla "afirmó de modo inequívoco la legitimidad de la preocupación de toda la comunidad internacional por la promoción y protección de los derechos humanos por todos y en todas partes». El Derecho internacional de los derechos humanos, op. cit., p. 88. 
primera conflagración mundial no sería, en lo absoluto, la guerra que pusiera término a todas las guerras -como entonces se proclamó-, las declaraciones y los tratados no han bastado para asegurar en definitiva el respeto a los derechos humanos de manera completa y general. Sucede, además, que ahí donde la tutela internacional «es posible, no es siempre necesaria, y donde sería necesaria, no siempre es posible " ${ }^{66}$. Además, no es infrecuente observar actitudes contradictorias de algunos gobiernos: «entre más autoritario es un gobierno con respecto a la libertad de sus propios ciudadanos, es más libertario [...] en su confrontación con la autoridad internacional ${ }^{67}$.

\section{Universalidad de los Derechos. Norma nacional y norma interna- cional}

Por su propia naturaleza, los derechos humanos tienen pretensión de

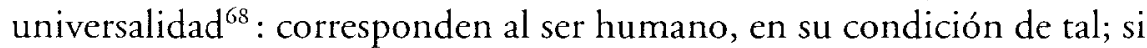
bajo las cartas medievales hubo grandes conjuntos marginados ${ }^{69}$, no hay personas fuera del imperio de las declaraciones contemporáneas;

66 Bobbio, L'età..., op. cit., p. 38.

67 Ibidem, p. 34.

68 «No se pueden pensar los derechos humanos sin algún tipo de universalidad. Lo que me parece más exacto -escribe Mauricio Beuchot- es decir que esa tensión entre lo universal y lo particular de los derechos humanos se equilibra no postulando que es algo que se va acordando en cada contexto y por eso se hace universal, sino que se va acordando en cada contexto precisamente porque es universal [...]. Ardua labor la de buscar los fundamentos de la universalidad de los derechos humanos. Pero si no tiene(n) algún tipo de universalidad, es claro que no funcionarán como tales derechos». "Los derechos humanos y el fundamento de su universalidad», Javier Saldaña (coord.), Problemas actuales sobre derechos humanos. Una propuesta filosófica, México, UNAM, Instituto de Investigaciones Jurídicas, 1997, pp. 58-59.

69 Porque los derechos otorgados constituían "una ley a favor de los privilegiados" (Cff: Dorn, Herbert, «Los derechos humanos como fuerzas formativas del desarrollo cconómico y social", en Academia Interamericana de Derccho Comparado e Internacional, Cursos monográficos, La Habana, 1953, vol. III, pp. 152-153) o bien, dicho en otras palabras, «las libertades medievales tenían como sujetos entidades corporativas, de modo que las libertades disfrutadas por el hombre lo eran en tanto fuese miembro de tales corporaciones". Manuel García Pelayo, Derecho constitucional comparado. Cuadernos de la Revista de Occidente, $7^{2}$. ed., Madrid, 1964, p. 141. 
éstas y los pactos que tienen a la vista ciertas categorías de sujetos, sólo distinguen o se especializan para equilibrar la suerte de algunos con la suerte de todos: se trata, en fin, de igualar, no de discriminar ${ }^{70}$. En cambio, los derechos humanos se consagran -se reconocen, se atribuyen, se tutelan: como se prefiera- en tanto el sujeto es persona, ser humano, mujer, varón, sin otro título que lo abarque o lo mejore, que lo exalte o lo distinga.

Aunque no se atraiga el concepto de derecho natural, los derechos humanos tienen un sentido esencial, radical, que proviene de una honda justificación en el dato mismo de «humanidad», una condición que es al mismo tiempo una razón ${ }^{71}$ para construir sobre este cimiento todo

$70 \mathrm{Me}$ refiero, por supuesto, al gran número de instrumentos específicos, destinados -en su proyecto nuclear- a la protección de grandes grupos o pequeños conjuntos, que se encuentran en situación de mayor vulnerabilidad; así, sólo por ejemplo, Declaración sobre los derechos de las personas pertenecientes a minorias nacionales o étnicas, religiosas y lingüisticas (Naciones Unidas, 1992), Declaración sobre la eliminación de la discriminación contra la mujer (Naciones Unidas, 1967), Convención sobre la eliminación de todas las formas de discriminación contra la mujer (Naciones Unidas, 1979), Declaración sobre la eliminación de la violencia contra la mujer (Naciones Unidas, 1993), Declaración de los Derechos del Niño (Naciones Unidas, 1959), Convención sobre los derechos del niño (Naciones Unidas, 1989), Declaración mundial sobre la supervivencia, la protección y el desarrollo del niño y Plan de Acción para la aplicación de la Declaración mundial (Cumbre Mundial a favor de la Infancia, 1990), Reglas minimas para el tratamiento de los reclusos (Naciones Unidas, 1957 y 1977), Principios básicos para el tratamiento de los reclusos (Naciones Unidas, 1990), Convenio sobre la libertad sindical y la protección del derecho de sindicación (OIT, 1948), Declaración de los derechos del retrasado mental (Naciones Unidas, 1971), Declaración de los derechos de los impedidos (Naciones Unidas, 1975), Convención internacional sobre la protección de los derechos de todos los trabajadores migratorios y sus familiares (Naciones Unidas, 1990), Convención interamericana para prevenir, sancionar y erradicar la violencia contra la mujer (OEA, 1994), Convención interamericana para la eliminación de todas las formas de discriminación contra las personas con discapacidad (OEA), etcétera.

71 La justificación de los derechos humanos «no puede encontrarse en el derecho positivo mismo, sino en el orden de la justicia. La formulación de los derechos humanos en la jurisprudencia existente en un Estado, puede verse como el reconocimiento de una razón que justifica esos derechos. Esa razón no puede ser sino la aceptación de un valor que, por ser común, debe ser asumido por todos; los principios de justicia se reducen a proclamar la vigencia, igual para todos, de ciertos valores [...]. La aceptación de los derechos humanos supone entonces la de un orden ético del que se derivan los principios de justicia que debe cumplir el orden jurídico". Luis Villoro, El poder y el valor. Fundamentos de una ética politica, $1^{\mathrm{a}}$. ed., $1^{\text {a }}$. reimp., México, El Colegio Nacional/Fondo de Cultura Económica, 1998, pp. 302-303. 
el edificio del Derecho, la sociedad y el Estado ${ }^{72}$. No sobra decir, por cierto, que ese universalismo entra en crisis cuando se enfrenta a una realidad imperiosa, que pone frente a frente a quienes pueden satisfacer sus mayores necesidades -y otras de menor envergadura-, y a quienes se hallan, de facto, impedidos para hacerlo ${ }^{73}$. ¿Cuál es, paradójicamente, la geografía del universalismo?

Desde luego, universalismo no es equivalente a globalización o mundialización, un proceso que ha encendido la polémica. En el viento de la universalidad soplan corrientes devastadoras, que han engendrado protestas crecientes en cada plaza donde la mundialización aparece, encarnada y flagrante -los hechos de julio del 2001, en Génova, son apenas un eslabón en la cadena ${ }^{74}$-, y han suscitado la crítica de un buen sector del pensamiento moderno, que denuncia el choque frontal entre la ideología del constitucionalismo, en su más luminosa versión, y la ideología de la mundialización económica ${ }^{75}$. Es evidente que esas co-

72 Los derechos humanos son "un referente inexcusable de la modernidad», su "signo distintivo"; en "los Estados democráticos los derechos se han convertido en una escala de evaluación de la legitimidad de los poderes públicos", indica Miguel Carbonell en su artículo "Los derechos en la era de la globalización", en Miguel Carbonell y Rodolfo Vázquez (comps.), Estado constitucional..., op. cit., p. 325.

73 Ha surgido una antinomia: "la existente entre el universalismo de los derechos fundamentales y su realización en los límites estatales a través de la ciudadanía". No es suficiente ser persona; hay que ser, además, ciudadano. Ferrajoli, «Más allá de la soberanía...", Miguel Carbonell y Rodolfo Vázquez (comps.), Estado constitucional..., op. cit., pp. 315-316.

74 Hechos que convirtieron a Génova en una «zona de guerra. Italia no había presenciado semejante violencia en varias décadas"; una violencia que empañó el "primer momento de gloria internacional" del nuevo gobierno de Silvio Berlusconi. "After the Genova summit, Picking up the pieces», en The Economist, Inglaterra, july 28thaugust 3rd 2001, p. 29. Fue así como la realidad estableció su propia presencia en lo que Berlusconi calificaría, ante el Senado, como "un éxito diplomático y político" para Italia. "M. Berlusconi tente de désamorcer la polémique sur les violences policières de Gênes", en Le Monde, Francia, dimanche 29-lundi 30 juillet 2001, p. 3.

75 «No se necesita demasiada perspicacia -escribe Pedro de Vega-para percatarse de que en el seno de una sociedad civil recorrida en su conjunto por los deplorables efectos de la mundialización económica, cualquier constructivismo ético de la vida política y social ha de verse inexorablemente condenado al más estrepitoso fracason. Chocan frontalmente la ideología del constitucionalismo y la ideología de la mundialización económica. "Mundialización y Derecho constitucional...", en Miguel Carbonell y Rodolfo Vázquez (comps.), Estado constitucional..., op. cit., pp. 175-177. Gerardo 
rrientes devastadoras ponen sitio a los derechos de un amplísimo conjunto, los relativizan -tanto, por lo menos, como el relativismo cultural- y finalmente los convierten, en el mejor de los casos, en utopía o ilusión.

La universalidad, que "arranca del humanismo laico de la Ilustración, como hubo antes otras propuestas de universalidad con otros orígenes ${ }^{76}$, puede ser observada desde diversos planos; en todo caso, «para mantener la imprescindible idea de universalidad a priori hay que elevarse desde las pretensiones morales concretas que respaldan cada derecho a la moralidad genérica que respalda al conjunto de los derechos ${ }^{77}$. Nadie debiera quedar excluido de los beneficios que entrañan los derechos humanos, y más estrictamente, nadie debiera hallarse al margen de las garantías jurisdiccionales y no jurisdiccionales que significan el medio precioso para la exigencia, la consolidación o la recuperación de esos derechos. A esto corresponde la idea de la universalidad de las cartas de derechos -declaraciones y pactos- y de las jurisdicciones contenciosas creadas a la luz de aquéllas. Bajo el mismo concepto se inscribe el regionalismo -europeo, americano, africano-, que ha dado grandes pasos adelante $^{78}$. No pugna, por lo demás, con la corriente universalista. Cada

Pisarello señala "desde un punto de vista jurídico-político, que en la medida en que los derechos de una parte creciente de la humanidad son enunciados cada vez más como mercancías, y no como auténticos derechos; esto es, indisponibles e innegociables, la globalización contradice y usurpa el principio ilustrado de universalidad concebido como un ideal de emancipación humana y, en ese sentido, de progreso moral". "Globalización, constitucionalismo y derechos: las vías del cosmopolitismo jurídico", en ibidem, p. 244.

76 Gregorio Peces-Barba Martínez, «La universalidad de los derechos humanos", en AAVV, La Corte y el sistema interamericano de Derechos Humanos, San José, Costa Rica, Rafael Nieto Navia, editor, Organización de los Estados Americanos/Unión Europea, 1994, p. 399.

77 «Si nos situamos en el plano lógico, por universalidad hacemos referencia a una titularidad de los derechos que se adscriben a todos los seres humanos. Sus rasgos son la racionalidad y la abstracción, congruentes con esa titularidad de todos los hombres. Si nos situamos en el plano temporal la universalidad de los derechos supone que tienen un carácter racional y abstracto al margen del tiempo y válidos para cualquier momento de la historia. $\mathrm{Si}$, por fin, nos situamos en el plano espacial, por universalidad entendemos la extensión de la cultura de los derechos humanos a todas las sociedades políticas sin excepción». Peces-Barba, ibidem, p. 401.

78 Es así que se ha "europeizado" el Derecho de los países de aquel Continente. Hoy se habla, inclusive, de un "Derecho constitucional nacional de Europa». Cfr. Peter Häberle, El Estado..., op. cit., p. 66 y ss. 
método tiene sus ventajas y contribuye a su manera en el gran objetivo común $^{79}$.

Los vientos de la globalización - «término poco agradable» ${ }^{80} \mathrm{y}$ concepto que requiere precisiones- ${ }^{81}$ soplan sobre los derechos humanos $y$ sugieren el replanteamiento de las grandes corrientes que han interesado o ahora interesan a la vida internacional. En punto donde concurren las reivindicaciones de soberanía, en un extremo, y de tutela de los derechos humanos, en el otro, con sus copiosas implicaciones en cada caso ${ }^{82}$. El fortalecimiento de las democracias liberales, tras el ocaso del comunismo, ha puesto en manos de algunos países la opinable «misión" de velar por los derechos humanos en su concepción liberal, arraigada en las tradiciones de Occidente, y en este mismo ímpetu se han ampliado las instancias internacionales de salvaguardia de esos derechos ${ }^{83}$. Sobra decir que en estas circunstancias resulta indispensable «repensar" con-

79 Héctor Gros Espiell considera que «universalismo y regionalismo deben coexistir, en un proceso recíproco de cooperación y estímulo, del que mucho puede esperarse, para la corrección o la atenuación de los factores que disminuyen o atenúan la eficacia y la efectividad de los sistemas internacionales de promoción y protección de los derechos humanos». Este autor -expresidente de la CIDH-observa que "puede ser peligroso que sólo exista un régimen regional, por las presiones y las afinidades políticas en la región, que en ciertos casos pueden ser factores negativos para la acción internacional, pero no es conveniente, en principio, que sólo exista un sistema universal, ya que, en ciertas situaciones, esto puede dificultar la acción internacional que, a su vez, puede ser en ocasiones más eficaz por el contacto, la proximidad y las afinidades regionales". "Universalismo y regionalismo...", en AAVV, Los tratados sobre derechos humanos..., op. cit., p. 15.

80 En expresión de Anthony Giddens, La tercera via. La renovación de la socialdemocracia, trad. de Pedro Cifuentes Huertas, México, Taurus, 1999, p. 40

81 "Uno de los problemas de la expresión globalidad es que la misma es considerada, al menos, como metáfora, descripción, ideal o necesidad", escribe Cossío, que también propone avanzar en el examen, todavía insuficiente, de la dimensión jurídica de la globalidad. Cambio social..., op. cit., p. 200 y ss.

82 Entre ellos, las posibilidades de intervención, que cubren un amplio elenco; "de la presión diplomática a las sanciones económicas y a la intervención militar». David Wippman, "Defending democracy through foreign intervention", en AAVV, El papel del Derecho internacional en América. La soberania nacional en la era de la integración regional, México, UNAM, Instituto de Investigaciones Jurídicas, 1997, p. 129.

83 Cfr: Miguel De la Madrid, "Soberanía nacional y mundialización", en AAVV, El papel del Derecho internacional..., op. cit., p. 15. 
ceptos tradicionales ${ }^{84}$; no para eliminarlos, en mi concepto, sino para conferirles vitalidad y persistencia en la nueva escena internacional.

No hay admisión pacífica del principio de universalidad ${ }^{85}$, que, por lo demás, tampoco excluye cierta consideración derivada de la diversidad cultural, ${ }^{86}$ ni hace de lado "alguna corrección conceptual», vinculada con datos históricos ${ }^{87}$. Recientes explicaciones colocan la pretensión

84 Por varias razones se sostiene que el Estado nacional constituye la "base de la organización política de los países y de la organización internacional. Al mismo tiempo, el concepto de soberanía entra en un proceso dinámico de adaptación, en el que será necesario encontrar un equilibrio entre la necesidad de mantener el Estado nacional y la de mejorar, perfeccionar y ampliar la competencia de la organización internacional". De la Madrid, ibidem, p. 18.

85 Así, Rodolfo Stavenhagen reexamina el tema bajo la óptica de los pueblos indígenas, "actores emergentes»; quienes defienden el relativismo «señalan que el mundo real está formado por una multiplicidad de grupos y pueblos culturales distintos, y que a menos que se reconozcan los problemas particulares relacionados de cada grupo, se trata simplemente de abstracciones sin sentido". Derechos humanos de los pueblos indigenas, México, Comisión Nacional de los Derechos Humanos, 2000, p. 17. Sobre los riesgos del relativismo, precisamente en lugares donde éste se presenta como medio para la protección de comunidades tradicionales, $f f$. Carbonell, "Los derechos en la era...", op. cit., 329.

86 Jesús González Amuchástegui examina los resultados de la Conferencia de Viena, a la luz de su Declaración final (un tema al que me refiero en los siguientes párrafos, desde la perspectiva de Huntington), y se pronuncia por "una reivindicación firme de la noción de humanidad", idea que "está en la base de un requisito que los filósofos morales coinciden en exigir a las normas morales, la universalidad"; se debe seguir "profundizando en la determinación consensuada (del) paradigma o standard de moralidad universal" al que deben conformarse las leyes internas; pero la "pretendida legitimidad universal de dicho standard moral debe ser compatible con el respeto y el reconocimiento de la diversidad cultural". Sin embargo, "dos matizaciones son urgentes: en primer lugar, este reconocimiento de la diversidad cultural no puede ser ilimitado; y en segundo lugar, la puesta en práctica de (los) derechos de los pueblos a la autodeterminación y a la identidad cultural debe ser cautelosa y prudente». "Derechos humanos: universalidad y relativismo cultural", en AAVV, La Corte y el sisterna..., op. cit., p. 215 y ss. Sobre los problemas que enfrenta el universalismo en África, donde es preciso considerar -y conciliar- las concepciones características de los mundos musulmán, occidental y "animista", cfr: Isaac Nguema, "Universalité et specificité des droits de l'homme en Afrique", en ibidem, pp. 361 y ss. Acerca del debate entre universalismo y relativismo cultural, cfr. María Dolores Prieto Davó, Economía abierta, globalización y derechos humanos, México, Comisión Nacional de Derechos Humanos, 2000, p. 44 y ss.

87 Germán Bidart Campos señala que "la universalidad de los derechos humanos no ofrece inconveniente con alguna módica corrección conceptual». Los derechos son 
occidental sobre la universalidad de los derechos humanos -como de otras creencias, costumbres, desarrollos- en el centro de la confrontación entre culturas ${ }^{88}$ : occidente querría extender sobre el mundo entero su modo de ver y querer la vida; pero otras culturas resisten: lo que para aquél es universalismo, para éstas es imperialismo ${ }^{89}$. No se hallan lejos los ecos de una controversia que cedió al cabo de la guerra fría entre el concepto «capitalista» de los derechos humanos y la democracia, y la noción "socialista" sobre los mismos extremos. Empero, la polémica no tiene hoy el eje ideológico, político y económico que tuvo, sino corre sobre las confrontaciones culturales - distancias y cercanías, que reconstruyen el mapa de las tensiones internacionales en la postguerra fría-; son ellas el motor de los nuevos conflictos.

A la vista de los debates y resultados de la Conferencia Mundial sobre Derechos Humanos, de Naciones Unidas (Viena, 1993), Huntington invoca las elocuentes expresiones de diversos participantes y observadores, que dan cuenta de una crisis generada por el cuestionamiento sobre la universalidad del concepto corriente de los derechos humanos. Se dice que «el régimen internacional de derechos humanos de 1945 [...] ya no existe [...]. El mundo es ahora tan árabe, asiático y africano como occidental. Hoy la Declaración Universal de los Derechos Humanos y los Pactos Internacionales son menos relevantes para gran parte del pla-

debidos al hombre, en todas partes, "pero conforme a la situación histórica, temporal y espacial que rodea a la convivencia de (los) hombres en (el) Estado [...]. El modo de realización de los derechos exigido por el valor es, por propia naturaleza y vocación de encarnadura histórica del mismo valor, variable y dependiente de las situaciones sociopolítico-jurídicas". Teoria general..., op. cit. p. 45.

88 "Occidente, y particularmente los Estados Unidos, que sicmpre han sido una nación misionera, cree que los pueblos no occidentales deben comprometerse con los valores occidentales de democracia, mercados libres, gobierno limitado, derechos humanos, individualismo, imperio de la ley, y deben incorporar dichos valores a sus instituciones. En otras civilizaciones hay minorías que aceptan y promueven estos valores, pero las actitudes dominantes hacia ellos en las culturas no occidentales van del escepticismo generalizado a la oposición radical». Samuel P. Huntington, El choque de las civilizaciones y la reconfiguración del orden mundial, trad. de José Pedro Tasaus Abadía. Paidós, $1^{\text {a }}$. ed., reimp, 2000, p. 217. Occidente se esfuerza frente a otras sociedades por "promover los valores e instituciones políticos occidentales presionando (a aquéllas) para que respeten los derechos humanos tal y como se conciben en Occidente y para que adopten la democracia según los criterios occidentales". Ibidem, p. 220.

89 Cf: Samuel P. Huntington, El choque de las civilizaciones.., op. cit., p. 217. 
neta que durante la era inmediatamente posterior a la segunda guerra mundial ${ }^{90}$.

El punto de las jurisdicciones internacionales suscita numerosos temas relevantes. Uno de ellos, que hoy atrae la atención de políticos y juristas -y que merece el interés de los mexicanos, siempre en la víspera de reformas constitucionales, que en este caso serían pertinentes-, es el relativo a la relación entre las normas del orden jurídico internacional y las disposiciones del Derecho doméstico ${ }^{91}$. El examen de este asunto y las implicaciones que ha tenido en los ordenamientos nacionales nos ponen a la vista de un sistema en evolución, cuyo destino es predecible.

Sobre este punto hay diversas soluciones posibles. La primera en el tiempo, que largamente prevaleció sin oposición severa, sostiene el predominio del Derecho nacional en general sobre el Derecho de gentes; el argumento que esgrime es la soberanía. Una posición más moderada en este mismo campo sugiere el predominio de la Constitución nacional sobre las disposiciones internacionales, que prevalecerían, sin embargo, sobre otras normas domésticas. Hay soluciones que proponen la interpretación de los derechos humanos recogidos en la ley nacional a la luz del Derecho internacional, que de esta manera propiciaría el mayor y mejor alcance de aquéllos ${ }^{92}$. Otros tratadistas -sobre todo en el campo del Derecho internacional, por supuesto- acogen sin reticencia el predominio de ese orden jurídico sobre el régimen interno de los Estados, que se plantearía, inclusive, en el caso de los propios textos constitucionales: sobre ellos prevalece la norma internacional ${ }^{93}$.

90 O bien, en los términos de otro crítico: «Por primera vez desde que la Declaración Universal fue adoptada en 1948, están en primer plano países no impregnados completamente de las tradiciones judeo-cristianas y de derecho natural. Esa situación sin precedentes definirá la nueva política internacional de derechos humanos. También multiplicará las ocasiones de conflicto». Cit. Samuel P. Huntington, El choque de las civilizaciones..., op. cit., p. 233.

91 Es muy amplia la bibliografía sobre este punto, como acerca de los restantes que se examinan en este artículo. Entre las exposiciones panorámicas de publicación reciente, $c f r$ Germán Bidart Campos, "Jerarquía y prelación de normas en un sistema internacional de derechos humanos", en Eduardo Ferrer Mac-Gregor (coord.), Derecho procesal constitucional, México, Ed. Porrúa, 2001, pp. 665 y ss.

$92 C f r$, en cuanto al régimen argentino, Germán Bidart Campos, "La interpretación de los derechos humanos en la jurisdicción internacional y en la jurisdicción interna», en AAVV, La Corte y el sistema..., op. cit., p. 46.

93 Carlos Ayala Corao, que examina las relaciones entre norma nacional y norma 
La expresión más viva de esa superioridad se localizaría en el jus cogens, que no puede ser negado, desvirtuado o reducido por los Estados ${ }^{94}$, un concepto de antigua raíz, que proviene de Francisco de Vitoria y de su idea sobre una auctoritas totius orbis, y al que Francisco Suárez llamó jus praeceptivum. ${ }^{95}$. En esta dirección avanzó la Convención de Viena sobre el Derecho de los Tratados ${ }^{96}$, e incluso la Corte Interamericana de Derechos Humanos ha tenido oportunidad de conocer algún caso sobre esta materia ${ }^{97}$. Digamos, por último, que se ha considerado posible es-

internacional, se refiere -entre otros sistemas- a los ordenamientos que reconocen a ésta rango supraconstitucional; así, el caso de la Constitución de los Países Bajos, de 1956 (artículo 63: «si el desarrollo del orden jurídico lo requiere, un tratado puede derogar las disposiciones de la Constitución"), reformada en 1983; el artículo $83^{\circ}$ declara que un tratado prevalece sobre la Constitución si es aprobado por mayoría de dos tercios de los votos escrutados. También se refiere -citando al jurista costarricense Piza Rocafort- a los supuestos de las constituciones de Guatemala y Honduras. Cfr. "La jerarquía de los tratados de derechos humanos", en Juan E. Méndez y Francisco Cox (eds.), El futuro del sistema interamericano..., op. cit., pp. 141-142.

94 Los autores de raíz jusnaturalista fundan la ley positiva en la norma natural, independiente de la voluntad de los Estados; otra cosa postula el positivismo: la norma jurídica proviene de la voluntad de los Estados que pactan sus propios compromisos. Cfr. Pedro Pablo Camargo, Tratado de Derecho internacional, Bogotá, Temis, 1983, t. I, pp. 310-311.

95 Cfr. Antonio Gómez Robledo, Fundadores del Derecho internacional. Vitoria, Gentili, Suárez, Grocio, México, UNAM, Instituto de Investigaciones Jurídicas, 1989, p. 35 .

96 Dice, en efecto: «Es nulo todo tratado que, en el momento de su celebración, esté en oposición con una norma imperativa de derecho internacional general. Para los efectos de la presente Convención, una norma imperativa de derecho internacional general es una norma aceptada y reconocida por la comunidad internacional de Estados en su conjunto como norma que no admite acuerdo en contrario y que sólo puede ser modificada por una norma ulterior de derecho internacional general que tenga el mismo carácter" (artículo 53 ${ }^{\circ}$ ). Son normas de Derecho taxativo o jus cogens -escribe Alfred Verdross-, entre otras, las "reconocidas como tales por los pueblos civilizados, como el principio de que no tienen fuerza obligatoria los tratados inmorales y los que violan los principios de humanidad". Derecho internacional..., op. cit. p. 81. Cfr. Antonio Gómez Robledo, El ius cogens internacional (Estudio histórico crítico), México, UNAM, 1982.

97 Así, al tomar conocimiento de un tratado de 19 de septiembre de 1762, celebrado entre la tribu Saramaca y los Países Bajos, que concedió autonomía a los indígenas saramacas, asentados en el territorio actual de Suriname, en cuyos términos aquéllos se obligan, entre otras cosas, a capturar a los esclavos fugitivos y devolverlos al gobernador de Suriname, quien pagaría entre 10 y 15 florines por cada uno; una cláusula permitió, 
tablecer determinada prelación en el sistema de los tratados, favorable a los convenios internacionales sobre derechos humanos, que no sólo incorporan obligaciones de los Estados entre sí -sostiene esa corriente de opinión, acogida en la jurisprudencia de la CIDH-, sino ante la comunidad internacional en pleno y ante los individuos; son los intereses profundos de aquélla y de éstos lo que viene al caso en la hipótesis de los tratados sobre derechos humanos, y no exclusivamente las relaciones directas entre los Estados ${ }^{98}$.

Por cierto, cuando aludo a tratados sobre derechos humanos no me refiero sólo a los instrumentos que únicamente consideran esta materia,

asimismo, la venta de otros cautivos. Obviamente, semejante tratado sería nulo en la actualidad, en virtud del jus cogens superveniens. «Un convenio de esta índole no puede ser invocado ante un tribunal internacional de derechos humanos". CIDH, Caso Aloeboetoe y otros. Reparaciones (articulo 63.1 Convención Americana sobre Derechos Humanos). Sentencia de 10 de septiembre de 1993. Serie C No. 15.

98 Sobre el particular, la Corte Interamericana ha tomado en cuenta los criterios de otros órganos y tribunales, entre ellos el parecer de la Corte Internacional de Justicia, en Opinión Consultiva Reservas a la Convención para la Prevención y Sanción del Delito de Genocidio (1951). En la jurisprudencia de la Corte Interamericana, cfr. Opinión Consultiva $O C-2 / 82$, de 24 de septiembre de 1982, acerca de El efecto de las reservas sobre la entrada en vigencia de la Convención Americana: "los tratados modernos sobre derechos humanos, en general, $y$, en particular, la Convención Americana, no son tratados multilaterales del tipo tradicional, concluidos en función de un intercambio recíproco de derechos, para el beneficio mutuo de los Estados contratantes. Su objeto y fin son la protección de los derechos fundamentales de los seres humanos, independientemente de su nacionalidad, tanto frente a su propio Estado como frente a los otros Estados contratantes. Al aprobar estos tratados sobre derechos humanos, los Estados se someten a un orden legal dentro del cual ellos, por el bien común, asumen varias obligaciones, no en relación con otros Estados, sino hacia el individuo bajo su jurisdicción». Párr. 29. En el mismo sentido, cfr. Caso del Tribunal Constitucional. Competencia. Sentencia de 24 de septiembre de 1999, Serie C No. 55, párr. 41, y Caso Ivcher Bronstein. Competencia. Sentencia de 24 de septiembre de 1999. Serie C No. 54, párr. 42. Últimamente, la Corte Interamericana volvió sobre el tema en el Caso Hilaire, Excepciones preliminares, Sentencia de 1 de septiembre de 2001, párr. 94: la Convención Americana, al igual que los restantes tratados de derechos humanos, "se inspiran en valores comunes superiores (centrados en la protección al ser humano), están dotados de mecanismos específicos de supervisión, se aplican de conformidad con la noción de garantía colectiva, consagran obligaciones de carácter esencialmente objetivo, y tienen una naturaleza especial, que los diferencia de los demás tratados, los cuales reglamentan intereses recíprocos entre los Estados Partes y son aplicados por éstos, con todas las consecuencias jurídicas que de ahí derivan en los ordenamientos jurídicos internacional e interno". 
como el Convenio Europeo de Roma, los Pactos de Naciones Unidas o la Convención Americana, sino a cualesquiera acuerdos formales entre Estados -con rango de convenio, pacto o tratado- en que se abarcan uno o más derechos humanos, aunque éstos no sean el tema preferente o fundamental del instrumento. En otros términos, viene al caso la precisión que hizo la propia Corte Interamericana al emitir su Opinión Consultiva $O C-16$, en lo que respecta a la Convención de Viena sobre Relaciones Consulares, cuestión a la que me referiré infra, específicamente: aquí se alojan normas que cubren aquel ámbito (así, la información sobre el derecho a la asistencia consular, regulada por un precepto: artículo $36^{\circ}$ ), aun cuando el tema esencial de la Convención es el régimen de las relaciones consulares ${ }^{99}$. Por otra parte, hay que mencionar ahora, asimismo, que los derechos recogidos en los tratados no constituyen, en modo alguno, el "máximo" posible en esta materia, sino un "mínimo": así, «dejan sitio a derechos implícitos y a un mejoramiento de lo que esos tratados formulan». 100

En México, el artículo $133^{\circ}$ aborda y resuelve la cuestión: los tratados internacionales, es decir, el ius gentium convencional, forman parte

99 En la OC-16, la Corte Interamericana tuvo en cuenta, asimismo, sus propios desarrollos en la OC-1 (Cfr "Otros tratados" objeto de la función consultiva de la Corte (Artículo $64^{\circ}$ Convención Americana sobre Derechos Humanos), Opinión Consultiva OC$1 / 82$ de 24 de septiembre de 1982. Serie A No. 1; opinión, punto primero). En el párr. 76 de la OC-16, la Corte hizo ver que "México (Estado que pidió la opinión) no solicita al Tribunal que interprete si el objeto principal de la Convención de Viena sobre Relaciones Consulares es la protección de los derechos humanos, sino si una norma de ésta concierne a dicha protección, lo cual adquiere relevancia a la luz de la jurisprudencia consultiva de este Tribunal (se alude a la OC-1/82), que ha interpretado que un tratado puede concernir a la protección de los derechos humanos, con independencia de cuál sea su objeto principal». Una vez desarrollado su argumento, que se funda en las características de la función de asistencia consular en estos casos, la Corte concluye que el citado artículo $36^{\circ}$ "efectivamente concierne a la protección de los derechos del nacional del Estado que envía y puede redundar en beneficio de aquél». De ahí que esta disposición "concierna" a un derecho del individuo, cuya naturaleza se explora en otra parte de la Opinión Consultiva.

100 Germán Bidart Campos, Teoría general..., op. cit., p. 441. La Convención Americana hace ver que ninguna de sus disposiciones puede ser interpretada en el sentido de limitar o excluir derechos o libertades recogidos en otros ordenamientos. Interesa, sobre todo, la preservación de «otros derechos y garantías, que son inherentes al ser humano o que se derivan de la forma democrática representativa del gobierno" (artículo $29^{\circ}$ ). 
de la ley suprema de la Unión ${ }^{101}$. Existe, empero, una condición perentoria: que esos tratados, acuerdos internacionales de voluntad, se realicen en forma consecuente con la Constitución y que sean aprobados por el Senado de la República ${ }^{102}$. Se trata, pues, de un acto jurídico complejo, en el que se asocian la voluntad del Ejecutivo y la del Senado $^{103}$, no así la del Legislativo en su conjunto, que abarca a la Cámara de Diputados. Tampoco se inscriben en este marco las resoluciones, declaraciones y otros actos del Derecho internacional público ${ }^{104}$ en los que no se presenta ese acto complejo reclamado por la ley fundamental de la República, no obstante el valor que pudieran tener bajo una variable concepción que ayer negaba imperio jurídico a las declaraciones ${ }^{105} \mathrm{y}$

101 No se alude, sin embargo, a otra fuente de notable relevancia, cuyas aportaciones suelen preceder e informar las normas convencionales: la costumbre internacional. El silencio constitucional y jurisprudencial suscita interrogantes. $C f r$. Manuel Becerra Ramírez, "Derecho internacional...", en El Derecho en México.., op. cit., pp. 1389-1390.

102 “Esta Constitución -resuelve el artículo $133^{\circ}$ de la mexicana, que llegó a nuestra ley fundamental a partir del artículo $6^{\circ}$, inciso 2 , de la Constitución de los Estados Unidos de América-, las leyes del Congreso de la Unión que emanen de ella y todos los tratados que estén de acuerdo con la misma, celebrados y que se celebren por el Presidente de la República, con aprobación del Senado, serán la Ley Suprema de toda la Unión». Añade el precepto, en una patente manifestación del control difuso de la constitucionalidad, que no ha permeado, sin embargo, la actividad de los tribunales mexicanos: "Los jueces de cada Estado se arreglarán a dicha Constitución, leyes y tratados a pesar de las disposiciones en contrario que pueda haber en las Constituciones o leyes de los Estados". El precedente norteamericano señala: "Esta Constitución, y las leyes de los Estados Unidos que se expidan con arreglo a ella, y todos los tratados celebrados o que se celebren bajo la autoridad de los Estados Unidos, serán la suprema ley del país y los jueces de cada Estado estarán obligados a observarlos, a pesar de cualquier cosa en contrario que se encuentre en la Constitución o en las leyes de cualquier Estado». Cfr. comentario sobre la conexión entre ambos preceptos, en Ruperto Patiño Mánffer, "Comentario al artículo $133^{\circ}$ constitucional", en Derechos del pueblo mexicano. México a través de sus Constituciones, $4^{\mathrm{a}}$. ed., México, H. Cámara de Diputados, LV Legislatura, 1994, t. XII, p. 1175 y ss.

103 Es atribución del Presidente de la República "celebrar tratados internacionales, sometiéndolos a la aprobación del Senado" (artículo $89^{\circ}$ constitucional, fracción $\mathrm{X})$, y lo es del Senado "aprobar los tratados internacionales y las convenciones diplomáticas que celebre el Ejecutivo de la Unión» (artículo $76^{\circ}$, fracción I).

104 Cfr. Jorge Castañeda, Valor juridico de las resoluciones de las Naciones Unidas, México, El Colegio de México, 1967.

105 Las declaraciones universal y americana -señaló Eduardo Novoa Monreal"por sí mismas no tienen efecto normativo ni valen para imponer a un Estado determi- 
hoy se lo reconoce en forma creciente ${ }^{106}$, reconocimiento que se extiende explícitamente, por supuesto, a la Declaración Americana de los Derechos y Deberes del Hombre ${ }^{107}$.

En la pirámide normativa mexicana, la ley suprema domina al tratado. Durante mucho tiempo se entendió que los tratados tenían el mismo valor normativo que las leyes federales emanadas de la Constitución: ordenamientos que desarrollan, como las ramas de un árbol que prolongan el tronco -decía Mario de la Cueva-, los textos de la norma fundamenta ${ }^{108}$.

nado el reconocimiento o el respeto de los derechos de quienes viven en su territorio". Derecho a la vida privada y libertad de información, un conflicto de derechos, México, Siglo XXI Editores, 1979, pp. 16-17.

106 La Proclamación de Teherán, emitida por la Conferencia Internacional de Derechos Humanos el 13 de mayo de 1968, estableció: «La Declaración Universal de Derechos Humanos enuncia una concepción común a todos los pueblos de los derechos iguales e inalienables de todos los miembros de la familia humana y la declara obligatoria para la comunidad internacional" (punto 2). César Sepúlveda subraya que hoy día no es posible discutir el valor de las resoluciones internacionales para el orden legal y la sociedad de Estados. Precisa: «Unas de ellas pueden ser ya consideradas como derecho internacional general consuetudinario, otras como una interpretación autorizada de los preceptos de la Carta, unas más como nuevo derecho donde no lo había, y todavía existen otras que elaboran con mayor detalle y con mejor precisión normas básicas preexistentes». El Derecho de gentes..., op. cit, p. 112; asimismo, p. 164 y ss. En este punto del desarrollo del Derecho internacional, considero pertinente rectificar la opinión que sostuve, treinta años atrás, en alguno de mis primeros trabajos sobre la materia, acerca del carácter no vinculante de las grandes declaraciones de derechos. Cfr. mi libro Los derechos humanos y el Derecho penal, cuya primera edición apareció en 1976 bajo el sello de SepSetentas.

107 En 1949, el Comité Jurídico Interamericano entendió que la Declaración de Bogotá no creaba obligaciones convencionales entre los Estados y carecía de la condición de Derecho Internacional positivo. En 1975, Thomas Buergenthal consideró que el Protocolo de Buenos Aires, que enmendó la Carta de la OEA y atribuyó a la Comisión Interamericana la calidad de "órgano principal» de aquella organización, también modificó el carácter de la Declaración de 1948 en tanto elevó el Estatuto de la propia Comisión al rango de "parte integral de la Carta". Cfr. Christina M. Cerna, "International law and the protection of human rights in the Inter-American system: rethinking national sovereignty in the age of regional integration", en AAVV, El papel del Derecho internacional..., op. cit., pp. 214-215.

108 Cfr: Mario De la Cueva, Teoría de la Constitución, México, Ed. Porrúa, 1982, p. 113 y ss. 
La Suprema Corte de Justicia ha modificado aquella opinión ${ }^{109}$. Este tribunal sostuvo ya que los convenios internacionales poseen mayor rango que las leyes federales derivadas inmediatamente de la Constitución: aquéllos comprometen a la nación en su conjunto y rebasan los ámbitos asignados a la ley federal y a la ley local; plantean deberes en el plano regional o mundial y pueden versar sobre cualesquiera materias -con exclusión de las proscritas por la ley fundamental: por ejemplo, supresión de garantías ${ }^{110}$-, tanto las reservadas a los Estados como las atribuidas a la Federación.

Anteriormente, el mismo supremo tribunal mexicano consideró que había igualdad jerárquica entre las leyes del Congreso de la Unión emanadas de la ley suprema y los tratados internacionales ${ }^{111}$. El nuevo criterio $^{112}$ esgrime dos razones, como ya señalé: a) los tratados, "compromisos internacionales (,) son asumidos por el Estado mexicano en su conjunto y comprometen a todas sus autoridades frente a la comunidad

109 Sobre los diversos criterios sustentados por la jurisprudencia federal en esta materia, cfr. Loretta Ortiz Ahlf, "Jerarquía entre leyes federales y tratados", en AAVV, Propuestas de reformas constitucionales, México, Barra Mexicana, Colegio de Abogados, Themis, 2000, t. II, pp. 1045 y ss.; y Guadalupe Barrera y Carlos Montemayor "Incorporación del Derecho internacional en la Constitución mexicana», en Diego Valadés y Rodrigo Gutiérrez Rivas (coords.), Derechos humanos. Memoria del IV Congreso Nacional de Derecho Constitucional, México, UNAM, Instituto de Investigaciones Jurídicas, 2001, en Derechos Htumanos. Memoria..., op. cit., p. 172 y ss. En este trabajo se examina también el silencio constitucional en relación con la costumbre internacional, p. 183 y ss., así como la incorporación de decisiones judiciales de tribunales internacionales, p. 188 y ss.

110 Artículo $15^{\circ}$ constitucional: «No se autoriza la celebración [...] de convenioso tratados en virtud de los que se alteren las garantías y derechos establecidos por esta Constitución para el hombre y el ciudadanon. Este precepto fue invocado para objetar la suscripción, por parte del gobierno de México, del Estatuto de Roma (1998) que crea la Corte Penal Internacional.

111 Así, en P.C.192, Gaceta del Semanario Judicial de la Federación, No. 60, Octava Época, diciembre de 1992, p. 27. En foros profesionales se ha propuesto modificar la Constitución para que las leyes federales que emanen de la Constitución y los tratados internacionales guarden "igual jerarquía entre sí». Eduardo Revilla Martínez "Órgano facultado para celebrar y aprobar tratados", en AAVV, Propuestas de reformas..., op. cit., t. II, p. 645.

112 A.R. 1475/98, Sindicato Nacional de Controladores de Tránsito Aéreo, 11 de mayo de 1999, Novena Época, Pleno, SJFy su Gaceta, t. X, noviembre de 1999, tesis P. LXXVI]/99, p. 46. Materia: constitucional. Tesis aislada. 
internacional». En tales casos, el Presidente de la República suscribe como jefe de Estado y el Senado interviene como «representante de la voluntad de las entidades federativas"; y b) "en esta materia no existe limitación competencial entre la Federación y las entidades federativas». El Presidente y el Senado pueden obligar al Estado mexicano en cualquier materia, independientemente de que para otros efectos ésta sea competencia de las entidades federativas.

La renovadora tesis de la Suprema Corte de Justicia, que alienta la conveniencia de una enmienda constitucional sobre el procedimiento doméstico para la aprobación de los tratados, acaso con la participación de la Cámara de Diputados -como ha sugerido un sector de la doctri$\mathrm{na}^{113}$ y se ha propuesto en foros políticos ${ }^{114}$, alecciona sobre futuras

113 El tema ha sido examinado por Diego Valadés, quien apunta que la Constitución mexicana conserva una solución -la aprobación de tratados a cargo del Senado, únicamente- que ya no recogen otras constituciones. Además -advierte- por obra de la globalización o mundialización «el número de cuestiones que van siendo consideradas como propias de la comunidad internacional va en aumento, por lo que la competencia normativa del presidente y del Senado puede ensancharse de una manera prácticamente ilimitada". Constitución y democracia, México, UNAM, Instituto de Investigaciones Jurídicas, 2000, pp. 74-76. Leonel Pereznieto Castro examina el problema que se crea cuando un tratado versa sobre materia reservada a las entidades federativas. Sugiere que en estos casos intervenga una comisión dictaminadora de la Cámara de Diputados, que haga el planteamiento correspondiente al Senado, o bien, una comisión conjunta de ambas Cámaras que lleve recomendaciones a éstas. Sin embargo, en la propuesta de reforma constitucional que el mismo autor formula sólo alude al caso de tratados internacionales que «impliquen la modificación de legislación federal". Cfr. "Participación de las entidades federativas en la celebración de acuerdos interinstitucionales y los tratados que versen sobre derecho común", en AAVV, Propuestas de reformas..., op. cit., t. II, pp. 1072 y 1074.

114 Se sugiere "facultar a la Cámara de Diputados para aprobar tratados internacionales; se plantearon dos procedimientos que, sin obtener acuerdo, obtuvieron mayorías: a) facultar a ambas cámaras del Congreso para aprobar todos los tratados, y b) establecer una distinción legal por materia para que, en razón de su naturaleza, unos instrumentos pasen por la aprobación de ambas Cámaras y otros, sólo por el Senado; en todos los casos, el Senado es la cámara de origen". En este mismo trabajo se manifiesta la sugerencia de uenviar los instrumentos aprobados por el Congreso o, en su caso, por el Senado a las legislaturas locales con la finalidad de que éstas actualicen las leyes ordinarias a fin de iniciar el proceso de incorporación en sus respectivos ámbitos". Porfirio Muñoz Ledo (coord.), Comisión de Estudios para la Reforma del Estado, Conclusiones y propuestas, México, UNAM, 2001, p. 267. 
reformas constitucionales, que tendrían su base en el desarrollo de la vida jurídica internacional y en la posición que México asuma en esta materia.

También es relevante mencionar la posibilidad de que se abra la vía del amparo contra violaciones a derechos humanos recogidos en instrumentos internacionales -como ocurre en otros países- suscritos y ratificados por México, con aprobación del Senado. En el pasado, esta propuesta se miró con escepticismo ${ }^{115}$; acaso ya existen las condiciones, en este momento animado por la tutela de los derechos humanos, para que el juicio de garantías avance en la dirección que le permita tutelar tanto las garantías individuales que la Constitución consagra como los derechos humanos que otros instrumentos -integrados en el ordenamiento mexicano, bajo el artículo $133^{\circ}$ constitucional- reconocen.

Esta última es la propuesta -plausible, a mi modo de ver- que plantea el proyecto de reforma constitucional y de nueva Ley de Amparo elaborada por una comisión de respetables juristas ${ }^{116}$ bajo el auspicio de la

115 Así, el profesor Antonio Martínez Báez (que en este punto discrepaba explícitamente del parecer de Antonio Carrillo Flores): "la correlación de los sistemas de derechos humanos (es decir, garantías constitucionales mexicanas y derechos estatuidos por los textos internacionales) no alcanza a fundirlos en uno solo, y [...] la defensa mexicana de las garantías individuales, o sea el Juicio de Amparo, habrá de mantenerse para asegurar los derechos consagrados en nuestra Carta Magna, al través de sus conocidos mecanismos jurisdiccionales", al paso que "la instancia adecuada para intervenir en la defensa de esos derechos humanos supranacionales, habrá de residir en organismos especializados, de integración también plurinacional, que superen las naturales limitaciones de los tribunales domésticos o de carácter municipal". "Correlaciones entre la Constitución y los Pactos de las Naciones Unidas", en AAVV, Los tratados sobre derechos humanos..., op. cit., p. 28.

116 La Comisión de Análisis de Propuestas para una Nueva Ley de Amparo quedó integrada por los abogados Humberto Román Palacios (ministro de la Suprema Corte y coordinador general de la Comisión), Juan N. Silva Meza (ministro de la Suprema Corte), César Esquinca Muñoa (magistrado de circuito), Manuel Ernesto Saloma Vera (magistrado de circuito), Héctor Fix-Zamudio (académico), José Ramón Cossío Díaz (académico), Javier Quijano Baz (abogado postulante) y Arturo Zaldívar Lelo de Larrea (abogado postulante). Acerca de los trabajos realizados por esta Comisión, cfr: «Presentación" ("A la comunidad jurídica nacional»), en el volumen Proyecto de la Suprema Corte de la Nación de la Ley de Amparo Reglamentaria de los Articulos $103^{\circ}$ y $107^{\circ}$ de la Constitución Politica de los Estados Unidos Mexicanos, México, Suprema Corte de Justicia de la Nación, 2001, p. 10 y ss. 
Suprema Corte de Justicia de la Nación ${ }^{117}$, con la que se daría cumplimiento, además, a la exigencia del artículo 25.1 de la Convención Americana acerca de protección judicial, de la que infra me ocuparé. Habría que precisar, aunque la respuesta se desprende de una rigurosa lectura del texto de la propuesta, si la expresión «instrumentos internacionales generales» sólo abarca los tratados, en sentido estricto, criterio que comparto, o si es debido extenderla a todos los instrumentos sobre derechos humanos, lo que traería aquí el amplísimo número de declaraciones emitidas por órganos internacionales o en conferencias de este carácter, con la participación y la firma de México.

Conviene tomar en cuenta que no siempre se asigna el mismo valor a todos los tratados internacionales ${ }^{118}$, como antes señalé a la cabeza suelen ir -para un buen sector de la doctrina, la jurisprudencia y la legislación- los correspondientes a derechos humanos ${ }^{119}$, e inclusive entre

$117 \mathrm{El}$ proyecto sugiere este nuevo texto del artículo $103^{\circ}$ constitucional, con su correspondencia en la Ley de Amparo (artículo $1^{\circ}$ ): "Los tribunales de la Federación resolverán toda controversia que se suscite por normas generales o actos de autoridad que violen las garantías que consagra esta Constitución o los derechos humanos que protegen los instrumentos internacionales generales en la materia que estén de acuerdo con la propia Constitución, celebrados y que se celebren por el Presidente de la República, con aprobación del Senado". Cfr., las Exposiciones de Motivos de la reforma constitucional y de la propuesta Ley de Amparo, en Proyecto de la Suprema Corte de Justicia de la Nación de Ley de Amparo Reglamentaria de los Articulos $103^{\circ}$ y $107^{\circ}$ de la Constitución Politica de los Estados Unidos Mexicanos, México, SCJN, 2001, pp. 31-32 (Ley de Amparo) y 255-257 (Constitución). Cfr., igualmente, por lo que toca a la primera versión del proyecto, Arturo Zaldívar Lelo de Larrea, "Breves comentarios al proyecto de nueva Ley de Amparo", en Diego Valadés y Rodrigo Gutiérrez Rivas (coords.), Justicia. Memoria del IV Congreso Nacional de Derecho Constitucional I, México, UNAM, Instituto de Investigaciones Jurídicas, 2001,pp. 209 y ss. El primer párrafo del artículo $27^{\circ}$ de la nueva Constitución venezolana, de 1999 , estatuye: “Toda persona tiene el derecho de ser amparada por los tribunales en el goce y ejercicio de los derechos y garantías constitucionales, aun de aquellos inherentes a las personas que no figuren expresamente en esta Constitución o en los instrumentos internacionales sobre derechos humanos".

118 Cfr: Dicgo Rodríguez Pinzón, Claudia Martín y Tomás Ojea Quintana, La dimensión internacional de los derechos humanos. Guia para la aplicación de normas internacionales en el Derecho interno, Washington, Banco Interamericano de Desarrollo/ American University, 1999, p. 87 y ss.

119 En México se ha planteado: «Establecer la jerarquía normativa del sistema jurídico mexicano, ubicando en primer lugar a la Constitución y a los instrumentos 
éstos hay cierta jerarquía. De ello es muestra clara el régimen constitucional argentino, en el que aparecen cinco tipos de tratados: dos de ellos relativos a derechos humanos; unos, específicamente mencionados, con "nombre y apellido"; otros, "los demás tratados y convenciones sobre derechos humanos" ${ }^{120}$. También la muy reciente Constitución venezolana asigna el más alto valor al Derecho internacional convencional sobre derechos humanos ${ }^{121}$.

Los convenios referentes a derechos humanos tienen un rasgo diferencial, con respecto a los restantes actos similares del Derecho internacional: están «destinados a obligar a los Estados parte a cumplirlos dentro de sus respectivas jurisdicciones internas, es decir, a respetar en esas jurisdicciones los derechos que los mismos tratados reconocen directamente a los hombres que forman la población de tales Estados» ${ }^{122}$. Digamos, finalmente, que un sistema de control difuso de la constitucionalidad y de las normas del más alto rango preceptivo lleva a los jueces ordinarios a aplicar la norma internacional por encima de lo que prevengan las disposiciones de menor jerarquía.

Sea de esto lo que fuere, es evidente que resulta necesario abrir el ámbito del Derecho nacional a la recepción de las normas internacionales $y$, por ende, de las jurisdicciones de esta misma naturaleza. Tal es el

internacionales en materia de derechos humanos; en segundo lugar, al resto de los tratados y, por último, a las leyes federales y locales». Comisión de Estudios para la Reforma del Estado, Conclusiones..., op. cit., p. 272. En el mismo sentido, cfr. Ortiz Ahlf, "Jerarquía entre leyes...", en AAVV, Propuestas de reformas..., op. cit., t. II, p.1052.

120 Cfr. Jorge R. Vanossi, "Los tratados internacionales ante la reforma de 1994", en Martín Abregú y Christian Curtis (comps.), La aplicación de los tratados sobre derechos humanos por los tribunales locales, Buenos Aires, Centro de Estudios Legales y Sociales, 1997, pp. 106-107. Las categorías, desde la perspectiva de la Constitución argentina, son : tratados clásicos; tratados y normas vinculados con derechos humanos mencionados en el inciso 22 del artículo $75^{\circ}$ "y que, según el constituyente, formarían o constituirían en su conjunto un sistema"; "los demás tratados y convenciones de derechos humanos»; tratados de integración con los países latinoamericanos; y tratados de integración con Estados no latinoamericanos.

121 Artículo $23^{\circ}$ : «Los tratados, pactos y convenciones relativos a derechos humanos, suscritos y ratificados por Venezuela, tienen jerarquía constitucional y prevalecen en el orden interno, en la medida en que contengan normas sobre su goce y ejercicio más favorables a las establecidas por esta Constitución y la ley de la República, y son de aplicación inmediata y directa por los tribunales y demás órganos del poder públicon. 
compromiso contraído por Estados que suscriben convenios en materia de derechos humanos -como la Convención Americana, cuyo artículo $1^{\circ}$ es explícito sobre el deber de adoptar medidas que permitan la observancia de las estipulaciones del tratado-, y en este sentido habría que considerar futuras reformas al ordenamiento jurídico mexicano ${ }^{123}$, ahora que nuestro país ha ingresado en el espacio de jurisdicción contenciosa de la Corte Interamericana de Derechos Humanos ${ }^{124}$.

122 Germán Bidart Campos, «El artículo $75^{\circ}$, inciso 22 , de la Constitución nacional», en Martín Abregú y Christian Curtis (comps.), La aplicación de los tratados sobre derechos humanos por los tribunales locales, op. cit., p. 78.

123 Como la anunciada reforma al artículo $21^{\circ}$ constitucional, que actualiza la normativa constitucional a propósito de las decisiones de los órganos jurisdiccionales internacionales, e introduce al ordenamiento mexicano el régimen de la Corte Penal Internacional.

124 Desde luego, el tema de la recepción nacional de las normas internacionales que involucra el problema de la prelación normativa, pero no se reduce a él- se ha planteado dondequiera y ha producido numerosos estudios relevantes. $C f r$, para una revisión general, algunos de los trabajos contenidos en la obra de en Martín Abregú y Christian Curtis (comps.), La aplicación de los tratados sobre derechos humanos por los tribunales locales, Buenos Aires, Centro de Estudios Legales y Sociales, 1997. 